DOE/NASA/20370-20
NASA TM-82594

DOE/NASA/20370-20
NASA TM-82594

\title{
Aluminum-Blade Development for the Mod-0A 200-Kilowatt Wind Turbine
}

Bradford S. Linscott and Richard K. Shaltens National Aeronautics and Space Administration Lewis Research Center

and

A. G. Eggers

Westinghouse Electric Corporation

December 1981

Prepared for

U.S. DEPARTMENT OF ENERGY Conservation and Renewable Energy Division of Wind Energy Systems 


\section{DISCLAIMER}

This report was prepared as an account of work sponsored by an agency of the United States Government. Neither the United States Government nor any agency Thereof, nor any of their employees, makes any warranty, express or implied, or assumes any legal liability or responsibility for the accuracy, completeness, or usefulness of any information, apparatus, product, or process disclosed, or represents that its use would not infringe privately owned rights. Reference herein to any specific commercial product, process, or service by trade name, trademark, manufacturer, or otherwise does not necessarily constitute or imply its endorsement, recommendation, or favoring by the United States Government or any agency thereof. The views and opinions of authors expressed herein do not necessarily state or reflect those of the United States Government or any agency thereof. 


\section{DISCLAIMER}

Portions of this document may be illegible in electronic image products. Images are produced from the best available original document. 


\section{Aluminum Blade Development for the Mod.0A 200.Kilowatt Wind Turbine}

Bradford S. Linscott and Richard K. Shaltens

National Aeronautics and Space Administration

Lewis Research Center

Cleveland, Ohio 44135

and

\section{A. G. Eggers}

Westinghouse Electric Corporation

Pittsburgh, Pennsylvania 15236

December 1981

Work performed for

U.S. DEPARTMENT OF ENERGY

Conservation and Renewable Energy

Division of Wind Energy Systems

Washington, D.C. 20585

Under Interagency Agreement DE-AB29-76ET20370
This document is

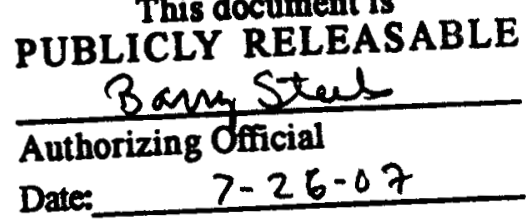


ALUMINUM BLADE DEVELOPMENT FOR THE MOD-0A 200-KILOWATT WIND TURBINE

\author{
Bradford S. Linscott and Richard K. Shaltens \\ National Aeronautics and Space Administration \\ Lewis Research Center \\ Cleveland, Ohio 44135
}

and

A. G. Eggers

Westinghouse Electric Company

Pittsburgh, Pennsylvania 15236

SUMMARY

Th is report documents the operating experience with two aluminum blades used on the DOE/NASA Mod-OA 200-kilowatt wind turbine located at Clayton, New Mexico. Each Mod-OA aluminum blade is 59.9 feet long and weighs 2, 360 pounds.

The aluminum blades originally used on the Mod-0, 100-kilowatt wind turbine test bed, near Sandusky, Onio, are ciescribed. The Mod-0 aluminum blacies were developed and tested before the Mod-OA aluminum blades were designed. Early Mod-0 blace tests showed a need for blades having higher load carrying capability. As a result, the MOd-OA blades were developed with the Mod-0 blades serving as prototypes.

The aluminum Mod-OA blade design requirements, the selected design, fabrication procedures, and the blade analyses are discusseci. A detailed chronology is presented on the operating experience of the Mod-OA aluminum blades used at Clayton, New Mexico. Blade structural damage was experienced. Inspection and damage assessment were required. Structural modifications that were incorporated to the blacies successfully extended the useful operating life of the blades. The aluminum blades completed the planned 2 years of operation of the clayton wind turbine. The blades were removed from service in August 1980 to allow testing of advanced technology wood composite blades.

\title{
INTRODUCTION
}

For the past several years the Federal Government has sponsored an expanding research and development program to make renewable energy sources for the generation of electricity a viable technological alternative to conventional generating capacity. One renewable energy source, wind energy, appears to be a particularly attractive candidate for the near term.

The Federal Wind. Energy program, under the sponsorship of the Department of Energy (DOE), is directed toward developing safe, reliable, costeffective, and environmentally acceptable machines to generate significant amounts of electricity. The largest element of the Federal program, large wind turbine development, is managed by the NASA Lewis Research Center. There are several ongoing wino system development projects oriented primarily toward utility application within this program element (refs. 1 and 2). 
The first-generation-technology large wind turbine called Mod-OA, has been designed and four units are in operation at utility sites. The first Mod-0A, rated at $200 \mathrm{kilowatts,} \mathrm{with} \mathrm{a} \mathrm{125-foot} \mathrm{diameter} \mathrm{rotor,} \mathrm{is} \mathrm{located}$ at Clayton, New Mexico; the second on the island of Culebra. Puerto Rico; the third on Block Island, Rhode Island; and the fourth on Oahu Is land, Hawai

The overall objective of the Mod-OA wind turbine project is to obtain early operation and performance data while gaining experience by operating in a typical utility environment. The first Mod-OA wind turbine started acceptance tests in November 1977 and became operational at the utility site in Clayton, New Mexico, in March 1978. It is shown in figure 1.

Because of limited funding and time allowed during 1976 and 1977, a 1 aboratory type of technology development phase of the Mod-OA project was not feasible. Instead, it was decided that wind turbine technology development would be conducted while utility operating experience was being gained.

The objectives for the development of the Mod-OA blades were (1) to test the blades on the wind turbine and not in the laboratory and. (2) as technology problems were found, to devise solutions and make the necessary modifications to allow continued testing of the blades. The experience gained as a result of testing the wind turbines on a public utility is part of a planned learning process to develop better performing and lower cost blades.

The Mod-OA blades are designed and constructed in much the same way as an airplane wing. During laboratory structural acceptance tests on airplane wings, detail structural design deficiencies are often found. The deficiencies are repairable by structural modification. Usually the modifications are isolated to a particular region. These problem areas are often called "hot spots." Like airplane wings, the wind turbine blades developed some "rot spots." As a result, the blades required structural modifications.

Details of the Mod-OA blade design and cperating loads are described in this report. During early testing of the blades, on the Clayton Mod-OA wind turbine, blacie structural damage was observed. As a result, structural repair to each blade was needed. The history of the Clayton Mod-OA structura 1 blace damage and the necessary repairs are summarized in this report. Details of the blade structural damage, inspection procedures, design changes and detailed structural modifications ore described in NASA Technical Memorandum 82595.

\section{ALUMINUM BLADES FOR THE MOD-O WIND TURBINE TEST BED}

The first wind turbine oesigned and constructed under the Federal wind Energy program was the Mod-0 wind turbine. This machine was installed by NASA at their Plum Brook Station near Sandusky, Ohio. Operation of Mod-0 began in September 1975. The purpose of Mod-0 was to provide a machine that allowed testing of advanced large horizontal ax is wind turbine technology concepts. The Mod- 0 was rated at 100 kilowatts in an $18 \mathrm{mph}$ wind and had a rotor diameter of 125 feet $(38.1 \mathrm{~m})$. The 59.9 foot $(18.3 \mathrm{~m})$ long blade first used on Mod- 0 were constructed of aluminum. These blades were manufactured for NASA by the Lockheed Aircraft Company, Burbank, California.

Alumirum blades were selected for Mod-0 because existing aircraft technology could be directly applied to the design, analysis and fabrication 
of these blades. This existing technology allowed Lockheed to design, fabricate, perform 7 imited tests, and deliver three blades to NASA within 8 months from start of design. The total cost for delivery of the three blades was approximately $\$ 300,000$, which included design, fabrication, and testing.

Because NASA designed the Mod-0 wind turbine, NASA provided Lockheed with certain blade specifications to assure compatibility of the blades with the machine. These specifications included the blade physical size and maximum weight, operating speed, pitch variation range, air loads, machine operational load cases, and associated operating times, for fatigue life analyses. As an example of additional specifications, figure 2 shows the blade chord, thickness, and twist angle distribution supplied to Lockheed by NASA. Complete details of all the design specifications are found in reference 3, which also documents the detailed loads and stress analys is performed by Lockheed to support the blade design. Reference 4 documents the blade dynamic analyses, weight and balance tests, and the structural and structural dynamic tests that were performed on the Mod-0 blades.

The Mod-0 blade planform is shown in figure 3. Each blade is 59.9 feet $(18.3 \mathrm{~m})$ long, so that the rotor assembly, including the hub, has a diameter of 125 feet $(38.1 \mathrm{~m})$. Each blade weighs 2000 pounds $(888 \mathrm{~kg})$. Strain gages, used to measure bending moments, are located at stations 40 and 367 (fig. 3). Station numbers refer to distances, measured in inches, from the axis of blade rotation.

A typical blade cross section is shown in figure 4 taken at station 300. The arrangement of the 0-spar structure and trailing edge structure can be seen clearly in this figure. Angle stringers and ribs as shown are used to prevent panel buckling of the skins under compressive loads. Steel and aluminum fasteners are used to assemble the various blade components.

The Mod-0 was first operated at rated power in variable wind speeds above $25 \mathrm{mph}(11 \mathrm{~m} / \mathrm{sec})$ during Uecember 1975. Blade loads were measured during these tests. These loads were found to exceed, by a factor of about 1.6, the load values used to design the blades. It was apparent that modifications to the machine were needed to allow continued safe, long-term operation of the blades.

Three key modifications to the machine were made. These modifications, described in references 5 and 6 , resulted in significantly reducing blade loads. First the tower stairway was removed. The stairway was used for manned access from the ground to the nacelle housing the rotating equipment. The second modification eliminated free play in the nacelle yaw drive system, and increased the yaw stiffness between the nacelle structure and tower. The third modification was the addition of a fluid coupling to prom vide damping in the high speed drive train (ref. 6).

Reference 5 shows that even with the modification, as described above, the observed steady state blade cyclic loads were about 10 percent higher than predicted. In addition, blade loads were affected by transients, such as wind gusts. These transient loads often exceeded the predicted operating loads used to design the blades. As a result, NASA contracted with the Lockheed Aircraft Company to conduct a study to define structural modifications for the Mod-0 blades. The modifications would allow the blades to safely operate under higher loads for the specified design life of 50,000 hours. The blade modifications proposed by Lockheed are reported in refer- 
ence 7. These proposed blade modifications served as the preliminary design for the Mod-OA aluminum blades.

\section{MOD-OA ALUMINUM BLADE DESIGN}

The Mod-OA blade design requirements, approach, selected design and supporting analyses are now discussed. Figure 5 shows an overall view of Mod-OA wind turbine during assembly. This figure shows the overall size and shape of the blades with respect to the rest of the machine.

\section{Design Requirements}

The Mod-OA blade design requirements are summarized in table $I$. The requirements include the blade dimensions, materials, and the airfoil type as well as the flapwise (normal to chord plane) and chordwise (in chord plane) cantilever natural frequencies. Figure 6 shows the design planform of the blade. Many additional details of the blade design were set including the thickness and chord distribution, the twist, the tolerances, the center of mass, a flutter requirement and the goal of a design life of 50,000 hours.

Operation at four loading cases was specified originally for design and analys is of the Mod-0 blades. The basic blade design condition, case 1 , is $40 \mathrm{rpm}$ with a wind velocity of ${ }^{1} 18 \mathrm{mph}(8.0 \mathrm{~m} / \mathrm{sec})$. Case 2 is a sudden wind gust from a 18 to $60 \mathrm{mph}(8.0$ to $27.0 \mathrm{~m} / \mathrm{sec})$ with no change in blade speed or pitch. Case 3 is a control failure from case 1 where the blade is suddenly feathered. Case 4 is a sudden drop in wind velocity to zero from case 1 without change in blade speed or angle. Mod-0 experience (ref. 5) showed that the measured blade loads are significantly larger than predicted for the case 1 operating condition. The allowable Mod-OA blade fotigue loads were therefore determined based on measured blade loads.

Environmental requirements include an operating temperature range of $-10^{\circ}$ to $120^{\circ} \mathrm{F}\left(-23^{\circ}\right.$ to $\left.50^{\circ} \mathrm{C}\right)$. Provision to prevent water accumulation in the blade was specified as a requirement. The blades are also required to be protected from damage due to moisture. The blades are required to withstand a hailstorm with 1-inch diameter hail without puncturing the skin or resulting in loss of contour.

Blade vibration and stress analyses were required to be performed by the manufacturer. The required analys is results included an interference diagram, vibration modes, vibratory stesses, combined stresses, fatigue limits, and expected life. The stress analysis was required to consider twisting, tension, and bending due to centrifugal forces, aerodynamic loads, gravity, and coriolis accelerations. Nondestructive tests were also required to verify natural frequencies, blade weight, and balance and to calibrate the strain gage instrumentation.

awind speeds at $30-$ foot $(9.1 \mathrm{~m})$ reference height. 
Approach

The Mod-0 blades were found to be basically satisfactory and, since the overall objective of the Mod-OA program was to obtain early operation and performance data while gaining experience in a utility environment, the Mod-OA blade design was based heavily on Mod-0. The Mod-OA blades are geometrically similar to the Mod-0 blade. Mod-OA was intended to operate for long periods of time and was expected to test the fatigue endurance of wind turbine components long before comparable experience could be accumulated on Mod-0. Therefore, since Mod-0 experienced higher blacie loads than expected (ref. 5), structural modifications were made to extend the fatigue life of these blades.

Selected Design

The Mod-OA wind turbine has a 125-foot-(38.1-nt) diameter hingeless rotor. Two aluminum rotor blades provide $200 \mathrm{ki}$ lowatts of shaft power at design conditions. The blades have a $33.8^{\circ}$ nonlinear twist with a NACA 23000 series airfoil. Externally they are essentially identical to the Mod-0 blades. The blade design requirements are summarized in table $I$. The blade chord, thickness and twist are shown in figure 2 (same for both Mod-0 and Mod-OA). The blade planform is shown in figure 6 .

Figure 7 shows a cross section of the blade, taken at stotion 300 , also called out in figure 6 . The forward portion of the cross section is called the D-spar. The aft portion of the cross section is called the trailing edge. The [-spar is a heavier and stronger portion of the blade, and as a result it carries most of the applied load. Angle stringers and ribs as shown are needed to prevent panel buck ling of the 0.08 and 0.31 inch 10.20 and $0.79 \mathrm{~cm}$ ) thick outer skins due to compressive load.

Detail A, called out in figure 7 is shown in figure 8 . This shows a typical method of attaching the angle stringers to the D-spar skin and rib. The steel Hilok fastener is an aircraft type of high strength shear bolt. close tolerance holes must be prepared so that there is an interference fit between each fastener and the hole. The interference fit allows the Hilok fastener to carry high shear loads. Aluminum rivets are typically used in the traiting edge portion of the blade.

Figure 9 shows the design details of the root end of the blade. A cylindrical steel tube is assembled by sliding it through the rib at station 48 and is mated and bolted to the rib at station 81.5 . The flange at station 31.75 provides the mechanical interface between the blade and the hub of the wind turbine.

The modifications from the Mod-0 design, incorporated to improve the fatigue strength of the Mod-OA blades, are as follows: (1) the spar cap thickness was increased, (2) trailing edge skin thicknesses were increased, (3) two spanwise stringers were added to each trailing edge surface, (4) the root end fitting. wall thickness was increased, (5) a closure plate was added to an inboard rib to seal the interior of the blade from the hub (to protect the hub mechanism), and finally,'(6) external doublers were added to all D-spar and trailing edge chordwise structural joints to increase the fatigue life. 


\section{Fabrication}

The leading edge skins are brake formed and assembled in sections in an assembly fixture, shown in reference 8 . The first skin segment of the leading edge is trimmed and spliced together with the second sk in segment, etc., until the leading edge is one complete assembily. Angle stringers and ribs are added and secured to the leading edge by the Hilok fasteners.

Aluminum skins, closing the aft opening of the D-spar, are called the 0 -spar closure panels. These skins run the full length of the blade and vary in thickness from $3 / 16$ inch $(0.48 \mathrm{~cm})$ near the blade root to $3 / 64$ inch $(0.12 \mathrm{~cm})$ at the blade tip. The D-spar closure panels are fastened to the angle stringers and to each 0-spar rib as typically shown in figure 7 . When assembly of the D-spar is complete, it is removed from the assembly fixture and placed in another fixture designed to allow assembly of the trailing edge structure to the 0-spar. Except for the 4340 steel blade root end fitting, al1 components are constructed of heat-treated 2024-T3 aluminum.

Al1 aluminum parts have a chemical film protective treatment against corrosion. All faying surfaces are wet sealed against moisture and air at assembly at structural joints.

All aluminum parts have a chemical film protective treatment. All faying surfaces are wet sealed to prevent entrapment of moisture and air at structural joints. All mechanical fasteners are wetted with sealant and then installed. Assembled parts are primed with epoxy and a final coat of polyurethane paint is added to guard against corrosion.

Strain gages, called out in figure 6 , installed on the blade root and in the blade midsection enable monitoring of flapwise bending, chordwise bending, and torison moments during operation. The gages are epoxy-sealed and a 11 wires are secured by clamps to the ribs and blade root. The wires terminate at a 55 pin standard electrical connector located at the root end of the blade. This connector provides the electrical interface between the blade and wind turbine. The 24 hole bolting flange at station 31.75 (shown in fig. 9) provides the mechanical interface between the blade and hub of the wind turbine.

\section{Supporting Analyses}

In the design of a rotor system, detailed consideration must be given to its dynamic characteristics to ensure a successful design. The items that generally require attention are blade frequency placement, blade flutter including wake effects, torsion flap-inplane stability, stall flutter, gust response, and effect of tower support and control system characteristics on coupled rotor-tower dynamic stability, response, and clearnace. Additionally, transient dynamic loads associated with system response during starting and stopping of the rotor system are important considerations.

The Mod-0 dynamic analys is performed by Lockheed, reported in detail in reference 4, included a detailed blade frequency analys is, a blade flutter analysis including wake aerodynamics, and an analys is of pitch-flap-lag stability and of the coupled rotor-control-tower dynamic response and stability characteristics. The computer programs used in these analys is efforts included a coupled-flap inplane frequency program, a blade flutter analysis program for which full-scale test correlation data was available 
(WINTUR), and a fully coupled multibladed rotor-body nonlinear aerodynamic anc dynamic analysis method (REXOR). Loads for design and correlation with measurements were obtained from the REXOR analysis.

Calculated blade frequencies show good separation from $\mathrm{nP}$ harmonic excitation sources. The inplane mode has excellent placement with respect to IP excitation. Coupled inplane and flapping motions occur due to the blade structural axis twist producing beneficial aerodynamic damping of the inplane mode. Results of the flutter analyses show that the blacie system is free from flutter.

The load calculation method (REXOR), verified by the Mod-0 experience (refs. 5 and 7), was used to predict blade loads for the Mod-OA wind turbine. The predicted blade loads at station 40 (shown in figs. 10 and 11) are taken from reference 9 . The dynamic analysis produces blade loads at two locations along the length. The detailed loading at other locations is cetermined from a beam analysis of the blade using the known loads at the two locations.

Blade fatigue life prediction (as discussed in ref. 10) entails many uncertainties. For example, there are many situations that might cause the tlade loads to exceed the design values, and untested structural details can cause concern regarding blade life prediction even under known load conditions. The curves in figures 10 and 11 show the results of a fatigue analysis that was made for the Mod-OA blade. The dashed lines show the highest loads that the blades can withstand without a loss of fatigue life. The analysis assumed (1) load distributions as specifieci previously (cases 1 through: 4) apply; (2) the wind turbine will operate at speeds up to the cutout wind speed; and (3) the quality of structure (design and manufacture) is comparable to that of an airplane wing (i.e., stress concentrations exist at some local structural details).

Many other load reversals can accumulate to damage the structure even though any one separately considered situation would produce loads that fall within ultimate strength limits. Operating conditions that cause load reversals that can accumulate to adversely affect fatigue include the following:

(1) Combinations of yaw angle, yaw rates, wind direction, and wind speed

(2) Rotor speed and blade pitch setting variations which may cause unanticipated load changes

(3) A large number of start-stop cycles

(4) Nonrotating loads during very high winds

(5) Load reversals due to varying amount of tower-flow-through blockage

(6) Fluctuations of electrical load demand

(7) Frequent actuation of emergency systems

(8) Site peculiar wind shears 
This section summarizes the experiences with the aluminum blades used on the Mod-OA wind turbine at Clayton, New Mexico. The blades, SN1004 and SN1005, began service on the wind turbine on November 30,1977 . The wind turbine was formally dedicated on January 28, 1978. The Clayton Light and Water Plant began routine operation of the machine on March 6, 1978. In June 1978, the Mod-OA blades were removed from the machine and shipped to NASA Lewis Research Center in Cleveland, Ohio, for repairs. The blades were reinstalled on the machine in September 1978. From June to September 1978 a set of Mod-0 aluminum blades were used to maintain continued operation of the Clayton wind turbine. Blade repairs were conducted at Clayton in June and September 1979 and in February 1980. The blades were removed from the machine in August 1980 and shipped to Lewis in Cleveland, Onio, for inspection. Inspection of the blades revealed that a significant amount of repair effort was needed to refurbish the blades to a useful condition. It was also estimated that the cost to repair the blades would have exceeded the planned funds available for blade repairs. As a result, blades 4 and 5 were retired from further Mod-OA wind turbine service.

Tables II to $V$ provide the operational chronology of the blades from the initial rotation through the end of the demonstration test. Each table lists the significant events, relative to the blades, noted during an operational time slice between repairs. Table Il also includes data pertinent to the set of Mod-0 blades that were used during the initial modification of the Mod-OA blades.

\section{Early Aluminum Blade Operating Experience}

Early measurements of blade loads during operation (ref. 8) indicated that the bloads were well below the design values. Blade loads were recorded continuously during the first few months of operation.

At some time following initial checkout, structural damage did accure (ref. 11). The first sign of difficulty found during a blade inspection was a discoloration adjacent to the heads of some fasteners. At a later inspection, fasteners were found to be loose and a crack in the D-spar sk in was found near station 81.5. Because excessive loads were not at first apparent, the initial assumption was that faulty workmanship during blade manufacture caused the structural damage. However, reexamination of some records showed that loads in excess of operating limits were encountered during nacelle yawing. Prime suspects for the high blade loads included the character of the wind (i.e., gusts and direction change), the function and stiffness of the yaw system, and the details of the shutdown procedures.

The wind turbine operated with little procedural change through September 1978 while the blade overloading was being investigated and while the initial blade repairs and modifications were made. After September 1978 a number of operational changes were made to attempt to eliminate or minimize blade overloading. The changes in turbine operation are follows:

(1) The "cutout" wind speed was decreased from $40 \mathrm{mph}(18 \mathrm{~m} / \mathrm{sec})$ to $35 \mathrm{mph}(15.7 \mathrm{~m} / \mathrm{sec})$. 
(2) The yaw brake caliper hydraulic pressure was increased when the machine is yawing to minimize chatter and increase damping.

(3) A low pressure switch was installed in the yaw brake hydraulic system to prevent yawing without proper caliper hydraulic pressure.

(4) The machine was shutdown whenever blade strain gage readings exceeded operating limits.

(5) The blade pitch change rate to feather the blades was decreased from $4^{\circ}$ per second to $]^{\circ}$ per second for shutdowns (except for overspeed shutdown).

\section{Evaluation of Blade Transition Structure}

Figure 12 shows a structural schematic of the blade. The left portion of the assembly is essentially a conventional airplane wing. Structurally, the skins provide most of the section moment of inertia required to resist the bending loads that result during operation. The ribs and stringers locate the skins to maintain the section shape. The right portion of the assembly, the root fitting flange is a standard machine flange. The zone between wing and machine is called the transition section (fig. 12).

In the transition section the "wing" loads carried by the blade skins are transferred through two inboard ribs to the flanged root fitting. The root fitting is rigidly bolted to the station 81.5 rib and slides through a penetration in the station $48 \mathrm{rib}$. The sliding interface in the station 48 rib (first rib) was provided to minimize thermal stress problems due to differential expansion between the steel root fitting and the aluminum blade structure.

Figure 13 shows a simplified structural model of the transition section. Note that the blade axial loads such as the gravity load (and centrifugal load) are transferred from the wing skins to the root fitting through the station $81.5 \mathrm{rib}$ and the tip of the D-spar web. The gravity load fully reverses each half revolution of the rotor, and this reverses the deflections of the rib and web producing a continuous sliding motion at the root fitting/station 48 rib interface. The blade bending loads are transferred to the root fitting primarily as shear loads at the two root fitting/rib interfaces. Note that, if the gap at the station 48 interface increases due to wear, bending of the station 81.5 rib will cccur as the gap at station 48 opens and closes. Also, significant shear forces will develop at the root fittina/station 81.5 bolts and the root fitting/D-spar web bolts. In addition, the steel root end fitting will. cyclicly impact the station 48 rib.

\section{Blade Problem Areas and Modifications}

In April 1978, NASA Lewis inspected the blades at Clayton. As a result of the inspection, two broken fasteners and several loose fasteners were found in the transition section on one of the blades. These fasteners were located between station 48 and 80 along the joint connecting the trailing edge to the D-spar. Recause blade structural damage was found, the blades were removed from the wind turbine in June 1978. The blades were then sent 
to the Lewis Research Center in Cleveland, Ohio, for a more thorough inspection of the structure.

During the blade inspection at the Lewis Research Center, three types of blade damage were found. Figure 14 illustrates the nature and location of the damage. The damage included (1) loose and broken fasteners, (2) wear, and (3) cracking. It was concluded that camatge at (1) was due to a design deficiency located along the line of fasteners joining the trailing edge sk in to the D-spar (fig. 15). It was determined that the joint could not carry the applied shear loads shown in figure 15. The shear loads occur primarily due to the chordwise bending moments, blade weight being a major contributor. As a result, broken and loose fasteners were found, and cracks were found in several angle stringers located in the root end of the D-spar. This design deficiency was corrected by adding doublers on the exterior of the blade between station 48 and 100 as shown in figures 16 and 17.

A second design deficiency was located at the bearing interface between the aluminum rib, at station 48 , and the steel root end fitting, shown in figure 18. It was observed during the blade inspection at the Lewis Research Center that the steel root end fitting had rubbed extensively on the station 48 aluminum rib during operation ( $f$ ig. 8 shows the detail design). This rubbing action caused excessive wear (damage at (2) in fig. 14) of the aluminum rib. The wear resulted in a radial clearance of up to 0.14 inch between the root end fitting and the rib on the blade. Because of the increased radial clearance at station 48, a large bending moment was applied to the rib at station 81.5 . It was concluded that the high bending moments applied to the station 81.5 rib caused the rib to crack and that the rib/D-spar skin contact forces caused the 0.25 -inch thick D-spar skin to crack (damage at (3) in fig. 14). The D-spar crack was repaired by the doublers shown in figures 16 and 17 which also effectively increase the skin thickness. A special bearing assembly (figs. 19 and 20) was designed and installed to solve the wear problem at the rib/root fitting sliding interface at station 48 . The redesign included a Be-Cu liner bonded to the inside diameter of the rib and a removable shim inserted between the rib and the root fitting.

The wind turbine was returned to service and operated satisfactorily with the repaired Mod-OA blades from September 25, 1978, to early February 1979. An inspection of the blades in February 1978 indicated that the Be-Cu liner bonded to each station 48 rib had separated from the ribs. A followon inspection in April showed broken and loose bolts in the double row of fasteners between the root fitting and D-spar closure panel (fig. 9). The wind turbine was shutdown when the broken and loose bolts were found, and the blades were removed from the machine for detail inspection. The inspection showed some additional cracking of the station 81.5 rib and a crack was found in the D-spar closure panel outboard of station 81.0 .

When the Be-Cu liner bond joint at station 48 rib failed, the liner shifted out of the rib producing a large gap ( $0.032 \mathrm{in.}$ ) between the root end fitting and rib. It was concluded that bending overloads in the station 81.5 rib had occurred again as the station 48 joints opened and closed, thus producing the observed amage. A new and modified liner (redesigned $\mathrm{Be}-\mathrm{Cu}$ ring) was installed in each blade. A shoulder was provided on the outside 
of the liner (in addition to the bond) to retain it. A structural doubler was installed to repair the web panel and the blades were reassembled.

The machine began operation again on June 19, 1979, but operated satisfactorily only until August when inspection again indicated a failure on one of the liner bond joints.

The wind turbine was shutdown on September 20, 1979, and the blades were removed to inspect for damange. Inspection showed some minor additional station 81.5 rib cracking and broken fasteners in the double row of fasteners between the root end fitting and 0-spar closure panel.

It was decided that the liner should not be retained by bonding alone. A new liner was designed that could be both mechanically attached and bonded to the station $48 \mathrm{rib}$. Figure 21 shows the two-piece, double shoulder aluminum bronze liner. Both segments of the liner are riveted to the $r i b$. Figure 22 shows the station 48 bearing assemly with the new liners.

The wind turbine was returned to service on September 26 , only 6 days after shutdown for repairs.

During a week ly inspection in January 1980, a crack was found on one of the blade skins. The crack occurred on Blade SN 1004 at station 102 in the main spar cap skin on the high pressure side. A portion of the doubler on this side of the blade was removed. Inspection of the crack path led to the conclusion that it had initiated at a rivet hole used to attach a doubler to repair old damage (location (1) of fig. 14). New doublers were riveted to the blade to repair the crack and permit the blade to be used for continued operation until the blades were removed from service in August 1980.

\section{Aluminum Blade Costs}

The process used to fabricate each aluminum blade is labor intensive. Each blade is comprised of several thousand individual parts. Most of the aluminum parts require a number of hand operations during each phase of fabrication and assembly. Four examples of the labor intensive U-spar fabrication and assembly process are sited. First, each U-spar skin panel is formed by several brake forming operations. Multi-brake forming is needed to obtain the proper three dimensional airfoil surface. Second, each panel is hand trimmed and fitted on assembly. Third, each panel is hand drilled, reamed, and deburred for fastener installation. Finally each panel is put through a chemical film treatment for corrosion prevention, and then painted.

Only six Mod-OA aluminum blades were built. As a result, it was not economical to invest in elaborate labor saving tooling and fixtures to build only a few blades. During 1977 the Mod-OA blades were assembled and delivered to NASA by the Lockheed Aircraft Services Company, Ontario, California, at a cost of $\$ 252,000$ per blade as reported in reference 12 . The structural modifications performed on the two Clayton blades during the summer of 1978 at NASA in Cleveland, Ohio, cost $\$ 70,000$ for labor and materials.

The aluminum blades have successfully served their intended purpose that is, to operate on the Clayton wind turbine for a 2-year test period. The aluminum blades were removed in August 1980 to allow testing of advanced technology wood composite blades. The wood composite blades, described in reference 13, for the Mod-OA wind turbine are manufactured by the Gougeon Brothers Inc., Bay City, Michigan. Each wood blade weighs 2600 pounds 
$(1180 \mathrm{~kg})$. This weight includes a 400 -pound $(182 \mathrm{~kg})^{\circ}$ adapter structure that interfaces between the wind turbine and the wood blade. The cost for each b lade, less adapter, is about $\$ 50,000$ when blades are purchased in small quantities. The wood composite blades have high potential for successful low cost operation on the Mod-OA wind turbine.

\section{CONCLUDING REMARKS}

The Mod-OA WTG in Clayton, New Mexico, completed 2 years of operation by the Clayton Light and Water Plant, a municipal utility. Uuring this period the blades, SN 1004 and SN 1005, accumulated over 5000 hours of operation. The following concluding remarks are a result of that experience:

(1) The blades successfully completed the 2-year test period al though periodic inspections, repairs, and modifications were needed.

(2) The blades exhibited satisfactory structural dynamic aeroelastic performance as predicted.

(3) The WTG periodically operated at higher wind velocities than were used as the basis for the fatigue life predictions.

(4) Modifications were developed to improve the blade fatigue life. These modifications were successfully applied on blades SN 1004 and SN 1005.

(5) The aluminum blades were removed in August 1980 to accommodate testing of wood composite blades. The wood composite blades have a higher potential for low cost than the aluminum blades used on the Mod-0A wind turbine.

\section{REFERENCES}

1. Robbins, W. H.; and Thomas, R. L.: Large Horizontal Ax is Wind Turbine Uevelopment. NASA TM-79174, 1979.

2. Kobbins, W. H.; Thomas, R. L.; and Baldwin, O. H.: Large Wind Turbines: A Utility Option for the Generation of Electricity, NASA TM-81502, 1980.

3. Cherritt, A. W.; and Gaidelis, J. A.: 100-kW Metal Wind Turbine Blade Basic Data, Loads and Stress Analys is. (LR-27153, Lockheed-California (Co.; NASA Contract NAS3-19235.) NASA CR-134956, 1975.

4. Anderson, W. U.: 100-kW Metal Wind Turbine Blade Uynamics Analys is, Weight/Balance, and Structural Test Results. (LR-27230, Lockheed-California Co.; NASA Contract NASA3-19235.) NASA CR-134957, 1975. 
5. Linscott, Bradford S.; et al.: Experimental Uata and Theoretical Analys is of an Operating $100 \mathrm{~kW}$ Wind Turbine. Proceedings of the Twelfth Intersociety Energy Conversion Engineering Conference, Washington, 0.C., Aug. 28-Sept. 2, 1977. Vo 1.2. American Nuclear Soc., 1977, pp. 1633-1650.

6. Sullivan, T. L; Miller, U. R.; and Spera, U. A.: Urive Train Normal Modes Analys is for the ERUA/NASA 100-Kilowatt Wind Turbine Generator. ERUA/NASA 1028-77/1, NASA TM-73718, 1977.

7. Letter Report on Task 111 - Correlation of Analytical and Actual Load Data and Task IV - Potential Structural Blade Modification. LR 27780 , Lockheed-California Co., Aug. 20, 1976.

8. Hunnicutt, C. L.; Linscott, B.; and Wolf, R. A.: An Operating 200-kW Horizontal Axis Wind Turbine. Selective Application of Materials for Products and Energy National SAMPE Symposium and Exhibition, 23rd, May 11-14, 1978, SAMPE, 1978, pp. 457-478.

9. Spera, U. A.; Janetzke, U. C.; and Richards, T. R.: Dynamic Blade Loading in the EROA/NASA $100 \mathrm{~kW}$ and $200 \mathrm{~kW}$ Wind Turbines.

ERUA/NASA/1004-77/2, NASA TM-73711, 1977.

10. Cardinale, S. V.: Executive Summary Report on Mod-OA Wind Turbine Blades Uperating Limitations. LR-28395, Lockheed-California Co., Jan. 1978.

11. Watts, George A.: Evaluation of Measured Blade Data - Mod-OA Wind Turbine. LR-28706, Lockheed-California Co., Aug. 1978.

12. Linscott, B. S. and Shaltens, R. K.: Blade Design and Operating Experiences on the Mod-OA $200 \mathrm{~kW}$ Wind Turbine at Clayton, N.M. Large Wind Turbine Vesign Characteristics and $R$ and $D$ Requirements, NASA CP-2106, CONF-7904111, 1979, pp. 225-238.

13. Gougeon, M. and Zuteck, M.: The Use of Wood for Wind Turbine Blade Construction. Large Wind Turbine Vesign Characteristics and $R$ and $D$ Jevelopments, NASA CP-2106, CONF-7904111, 1979, pp. 293-308. 


\section{TABLE 1. - MOD-OA BLADE DESIGN REQUIREMENTS}

Dimensions:

Length, ft $(\mathrm{m})$................ 59.9 (18.3)

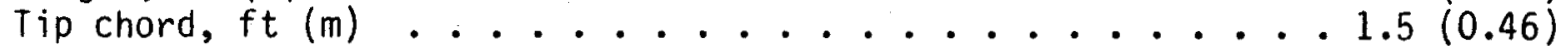

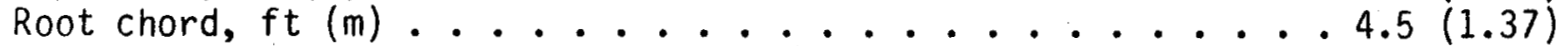

Chord taper,....................... L Liner

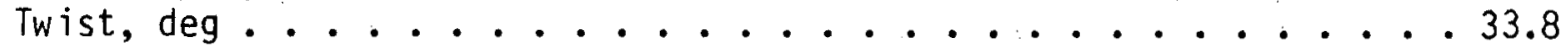

Materials:

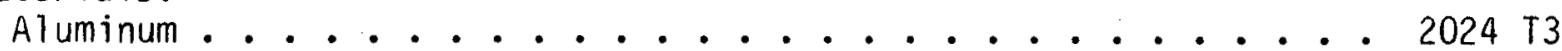

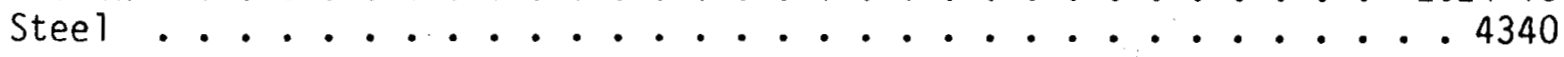

Ae rodynamic:

Airfoil ..................................... 23000

Solidity, percent .................... 3

Structural dynamics:

first flap, $\mathrm{Hz}$. . . . . . . . . . . . . . . . 1.5

First chord, $\mathrm{Hz}$. . . . . . . . . . . . . . . . . . 2.9

Instrumentation:

Strain gage locations:

Root end (station 40)

Midspan (station 370 )

Strain gage measurements:

Flap and chord bending

Torsion

Mechanical interface:

Circular bolting flange

24 5/8-in.-diameter high. strength bolts

Electrical interface:

MS connector, 55 pin

Blade weight, lb $(\mathrm{kg})$. . . . . . . . . . 2360 (1066) 


\section{TABLE 11. - OPERATIONAL CHRONOLOGY OF MOD-OA BLADES FROM STARTUP TO SEPTEMBER 1978}

[Utility operation began on March 6, 1978. The WTG had been checked out for approximately 200 hours at that time.]

\begin{tabular}{|c|c|}
\hline Date & Event \\
\hline No vember 30,1977 & First blade operation \\
\hline January 19, 1978 & Completed first 100 hours of operational checkout \\
\hline January 28,1978 & Formal dedication of WTG \\
\hline March 1, 1978 & Ice developed on blades during WTG operation \\
\hline March 28, 1978 & $\begin{array}{l}\text { First report of dusting of rivet heads and one } \\
\text { missing rivet head in trailing edge to, D-spar } \\
\text { connection }\end{array}$ \\
\hline May 24, 1978 & $\begin{array}{l}1000 \text { hours of utility operation }(94000 \mathrm{~kW}-\mathrm{hr} \text { ) when } \\
\text { trailing edge/0-spar fasteners in area of blade root } \\
\text { worked loose and creaking noise developed }\end{array}$ \\
\hline June 2, 1978 & $\begin{array}{l}\text { Shutdown WTG to inspect and replace Mod-0A blades; } \\
1124 \text { hours of utility time }\end{array}$ \\
\hline June 28,1978 & Installed Mod-0 blades; WTG returned to service \\
\hline September 11, 1978 & $\begin{array}{l}\text { Shutdown to install modified Mod-OA blades; Mod-0 } \\
\text { blades operated } 749 \text { hours }\end{array}$ \\
\hline September 25, 1978 & $\begin{array}{l}\text { Removed Mod- } 0 \text { blades and installed Mod-OA blades; } \\
\text { returned WTG to service }\end{array}$ \\
\hline
\end{tabular}


TABLE III. - OPERATIONAL CHRONOLOGY OF MOD-OA BLADES

FROM SEPTEMBER 1978 TO JUNE 1979

\begin{tabular}{|c|l|}
\hline Uate & \multicolumn{1}{|c|}{ Event } \\
\hline September 25,1978 & $\begin{array}{l}1873 \text { hours of utility operation (171 000 kW-hr) } \\
\text { when Mod-0A blades were reinstalled } \\
\text { Epoxy bonded linera separation on blade SN 1004 } \\
\text { at station 48 }\end{array}$ \\
February 6,1979 & $\begin{array}{l}3084 \text { hours of utility operation (286 000 kW-hr) } \\
\text { Epoxy bonded linera separation suspected on the } \\
\text { second blade (SN 1005) at station 48 } \\
\text { Anspection revealed one broken and two loose root } \\
\text { fitting attachment bolts in one blade } \\
\text { 3916 hours of utility operation (380 000 kW-hr) and } \\
3167 \text { hours of Mod-0A blade operation } \\
\text { Removed blades for field inspection and } \\
\text { installation of modified station 48 Be-Cu liners } \\
\text { JTG returned to service }\end{array}$ \\
June 19,1979 18,1979 & \\
\hline
\end{tabular}

acylindrical liner inserted into bore (and bonded in place) of each station 48 rib to repair wear that occurred prior to June 1978. 
TABLE IV. - CHRONOLOGY OF MOD-OA BLADES FROM

JUNE 19, 1979, TO SEPTEMBER 26, 1979

\begin{tabular}{|c|c|}
\hline Date & Event \\
\hline June 19, 1979 & WTG returned to service \\
\hline June 26, 1979 & $\begin{array}{l}3984 \text { hours of WTG utility operation } \\
\text { ( } 387 \text { 000 kW-hr) and } 3235 \text { hours of Mod-OA } \\
\text { blade operation. }\end{array}$ \\
\hline August 18,1979 & Station 48 linera separated in blade SN 1005 \\
\hline September 26, 1979 & $\begin{array}{l}\text { WTG shutdown - rotor removed from tower to } \\
\text { replace bolt and atation } 48 \text { liner; } 4933 \text { hours } \\
\text { of utility operation ( } 458000 \mathrm{~kW}-\mathrm{hr} \text { ) and } \\
4184 \text { hours of Mod-OA blade operation }\end{array}$ \\
\hline Sept. 21 to Sept. 25, 1979 & $\begin{array}{l}\text { Field inspection/modification of station } 48 \\
\text { rib linera }\end{array}$ \\
\hline September 26, 1979 & WTG returned to service \\
\hline
\end{tabular}

acylindrical liner inserted into bore (and bonded in place) of each station 48 rib to repair wear that occurred prior to June 1978. 
TABLE V. - CHRONOLOGY OF MOD-OA BLADES FROM

SEPTEMBER 26, 1979; to AUGUST 24, 1980

\begin{tabular}{|c|c|}
\hline Date & Event \\
\hline September 26, 1979 & $\begin{array}{l}4933 \text { hours of utility operation ( } 458000 \mathrm{~kW}-\mathrm{hr} \text { ) and } \\
4184 \text { hours of Mod-OA blade operation }\end{array}$ \\
\hline October 1, 1979 & $\begin{array}{l}5000 \text { hours of utility operation ( } 463000 \mathrm{~kW}-\mathrm{hr}) \text { and } \\
4251 \text { hours of Mod-0A blade operation }\end{array}$ \\
\hline January 6, 1980 & $\begin{array}{l}5843 \text { hours of utility operation }(535000 \mathrm{~kW}-\mathrm{hr}) \text { and } \\
5094 \text { hours of Mod-OA blade operation }\end{array}$ \\
\hline January 11, 1980 & $\begin{array}{l}\text { Discovered crack in D-spar of blade SN } 1004 \text { at } \\
\text { station } 102 \text {, WTG shutdown }\end{array}$ \\
\hline February, 1980 & $\begin{array}{l}\text { Ultrasonic inspection in the clayton Armory, returned } \\
\text { to service }\end{array}$ \\
\hline March 6, 1980 & $\begin{array}{l}\text { Completed } 24 \text {-month demonstration period; WTG operated } \\
\text { by utility } 6123 \text { hours, generated } 552000 \mathrm{~kW}-\mathrm{hr} \text { of } \\
\text { electricity, average power output } 90.2 \mathrm{~kW} \text {, Mod-OA } \\
\text { blade operating time } 5374 \text { hours }\end{array}$ \\
\hline August 24, 1980 & $\begin{array}{l}\text { Blades removed from WTG, inspected at NASA LeRC, and } \\
\text { removed from further WTG operation; } 7333 \text { hours of } \\
\text { utility operation }(677000 \mathrm{~kW}-\mathrm{hr}) \text { and } 6584 \text { hours of } \\
\text { Mod-OA blade operation }\end{array}$ \\
\hline
\end{tabular}


NASA

CS-78-284

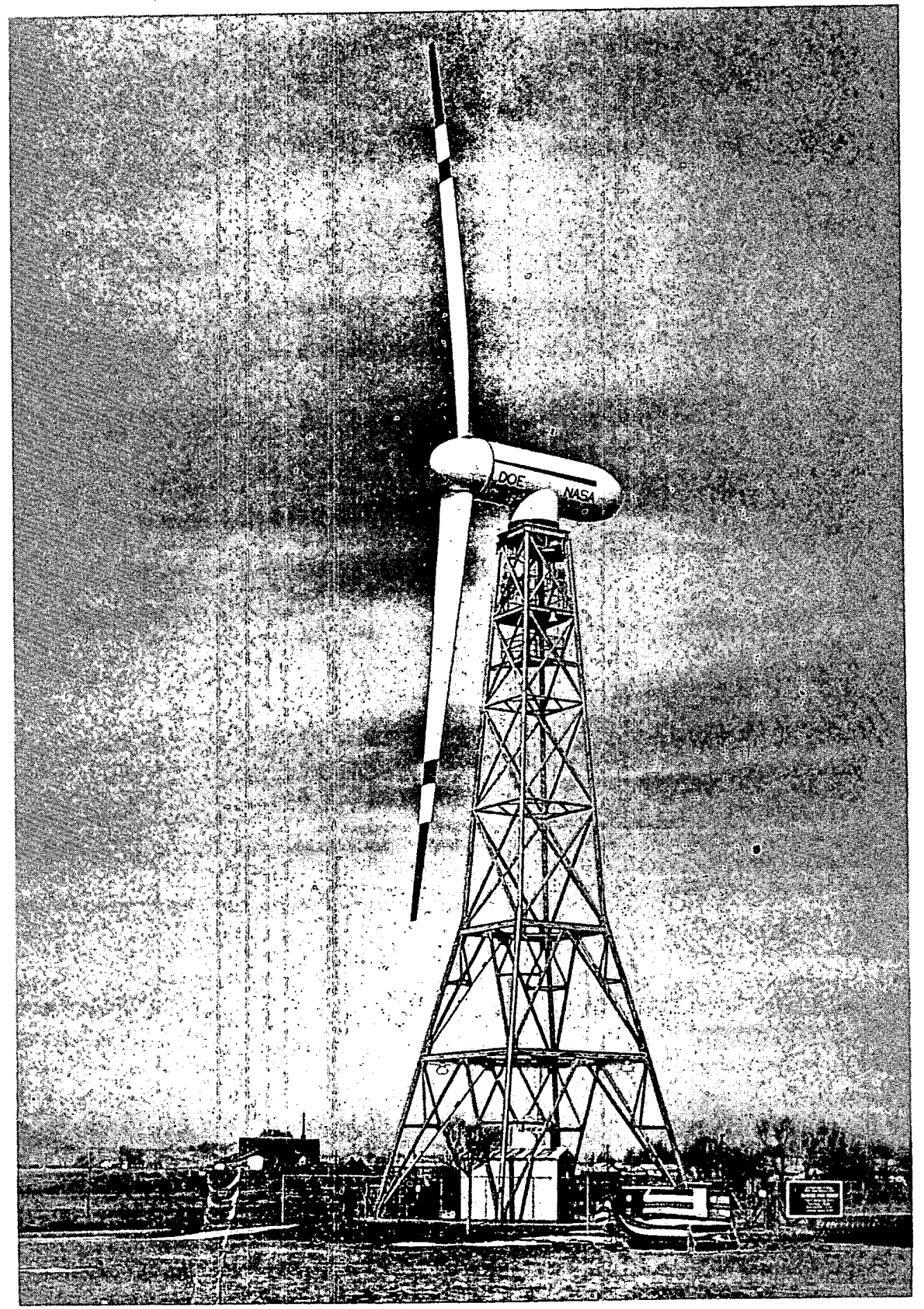

Figure 1. MOD-OA Clayton, NM 


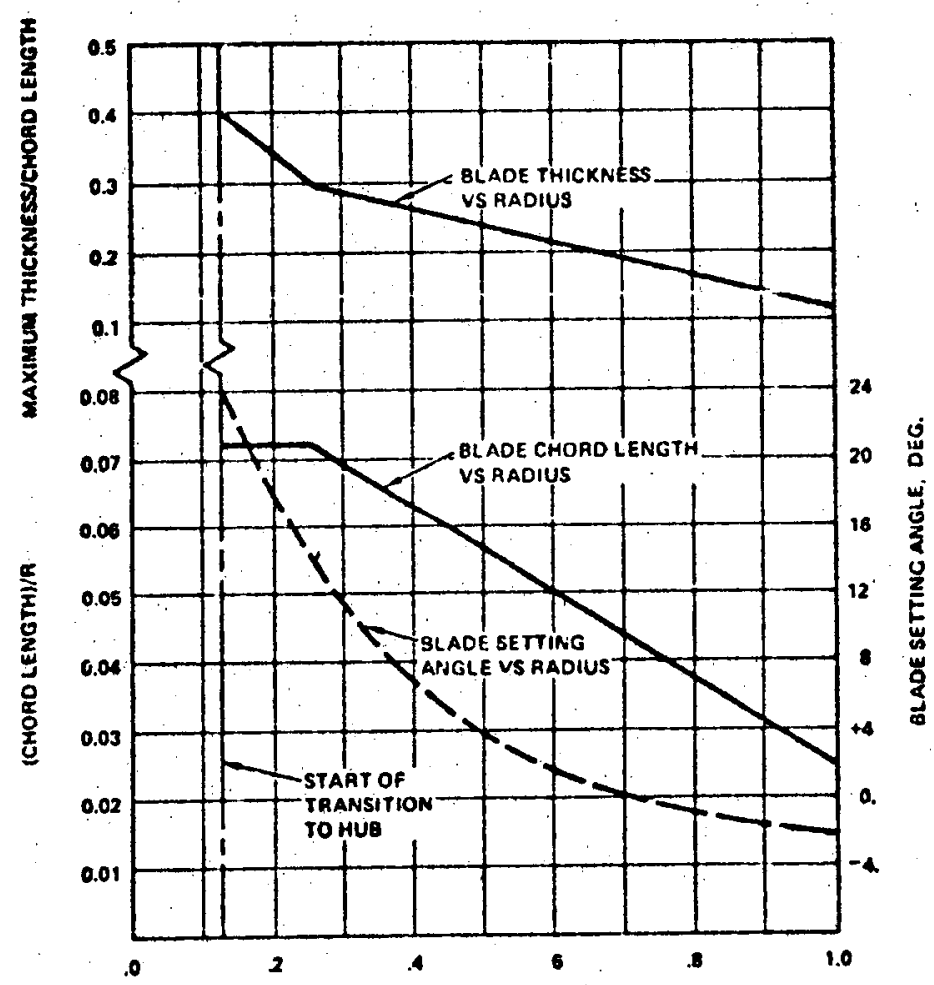

NORMALIZED RADIAL LOCATION $\mathrm{r} / \mathrm{R}$

Figure 2. - Blade geometry. 


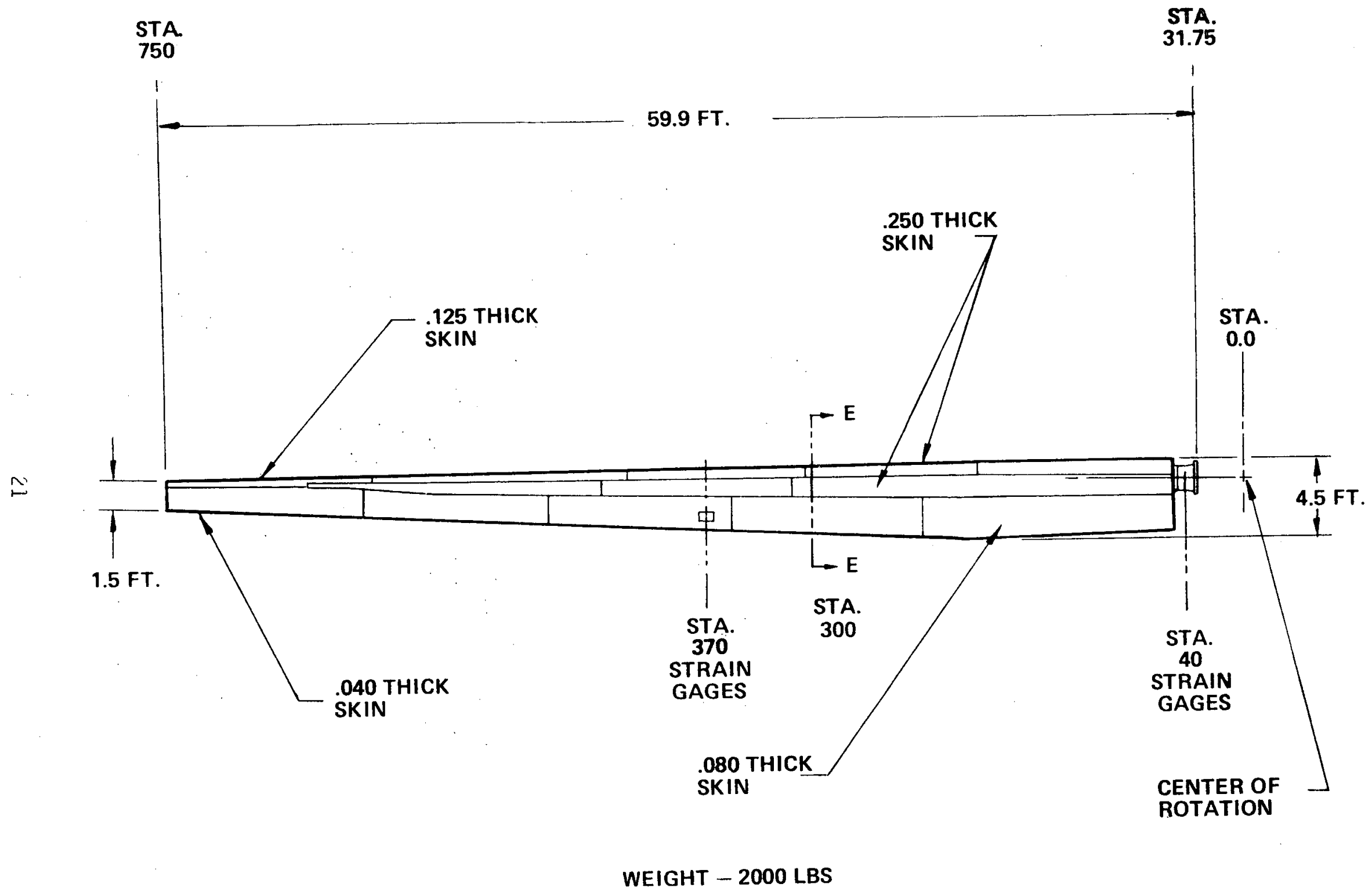

Figure 3. - Mod-0 blade configuration - planform. 


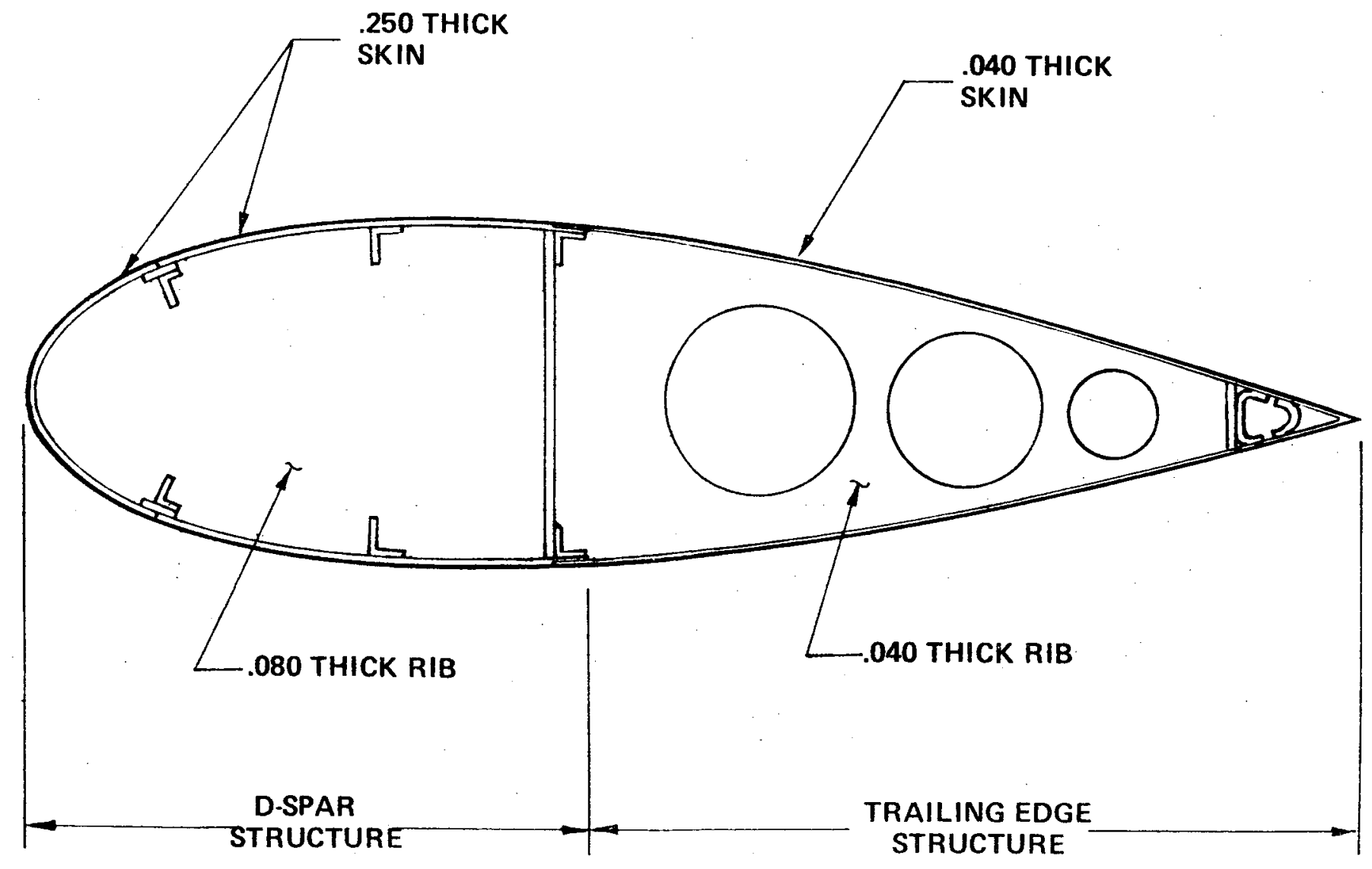

Figure 4. - Mod-0 blade typical cross section. 


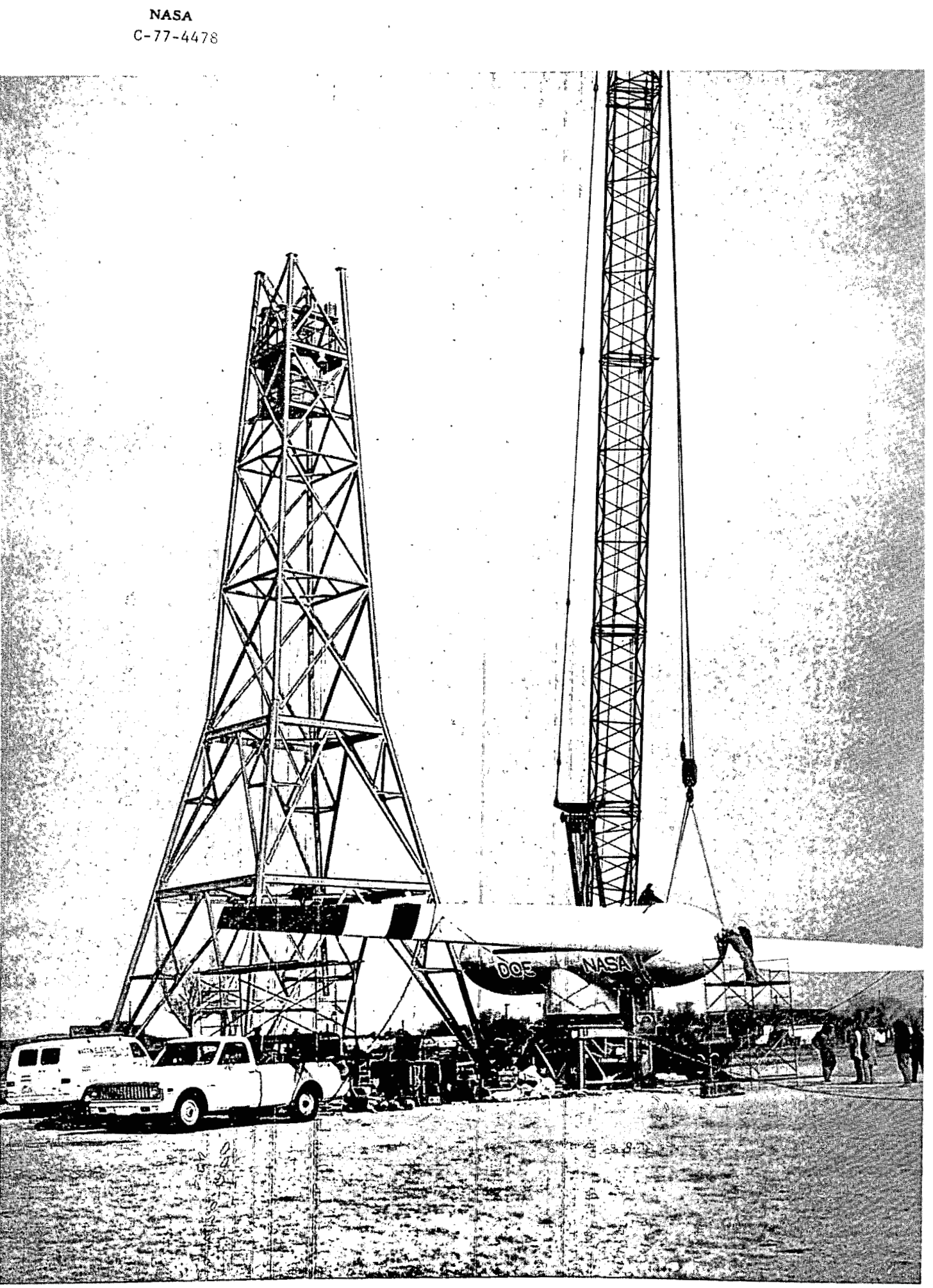

Figure 5. MOD-OA Nacelle/Rotor Assembly Ready for Installation on Tower 


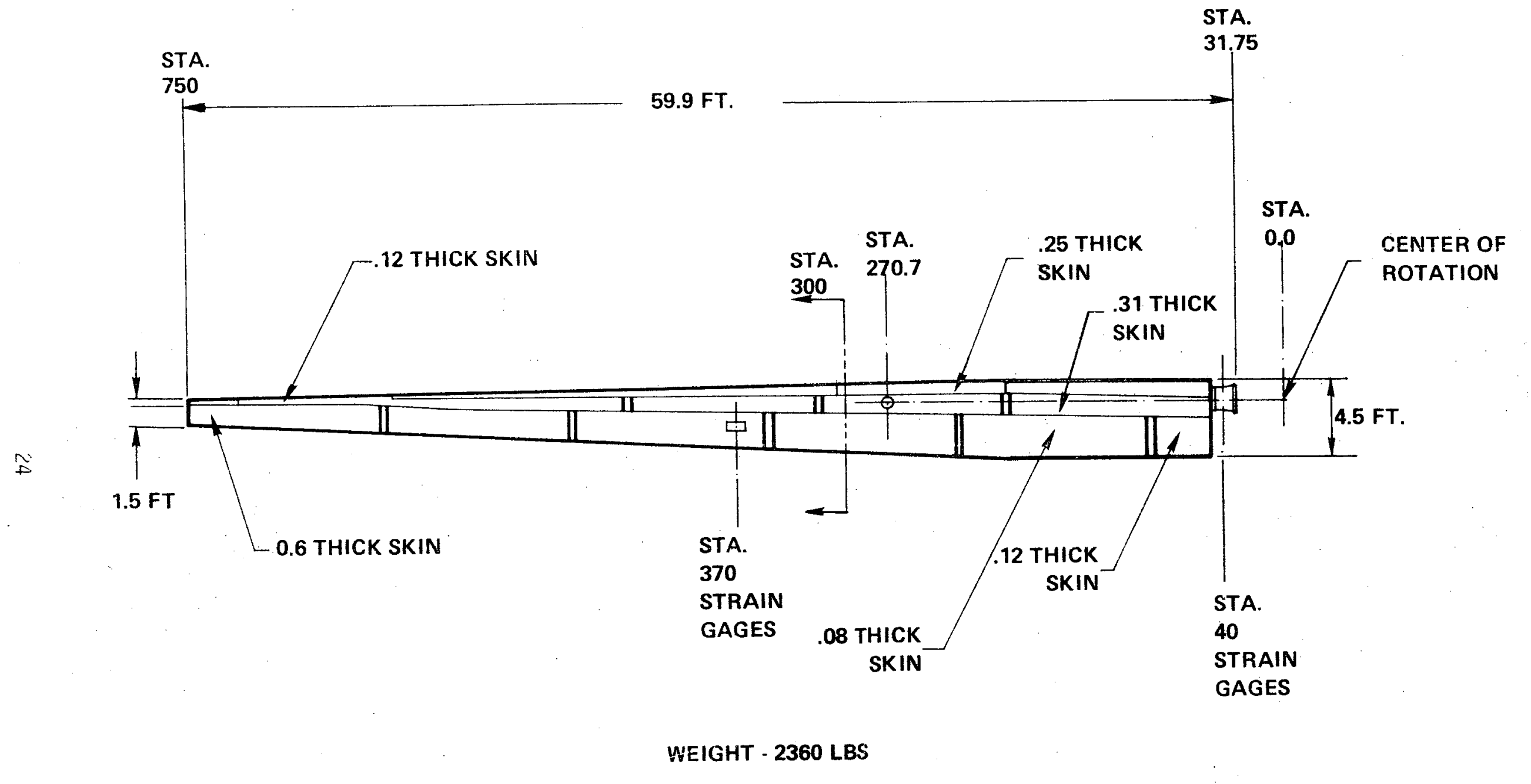

Figure 6. - Mod-OA blade configuration - planform. 
BLADE SECTION TAKEM AT STA. 300 .

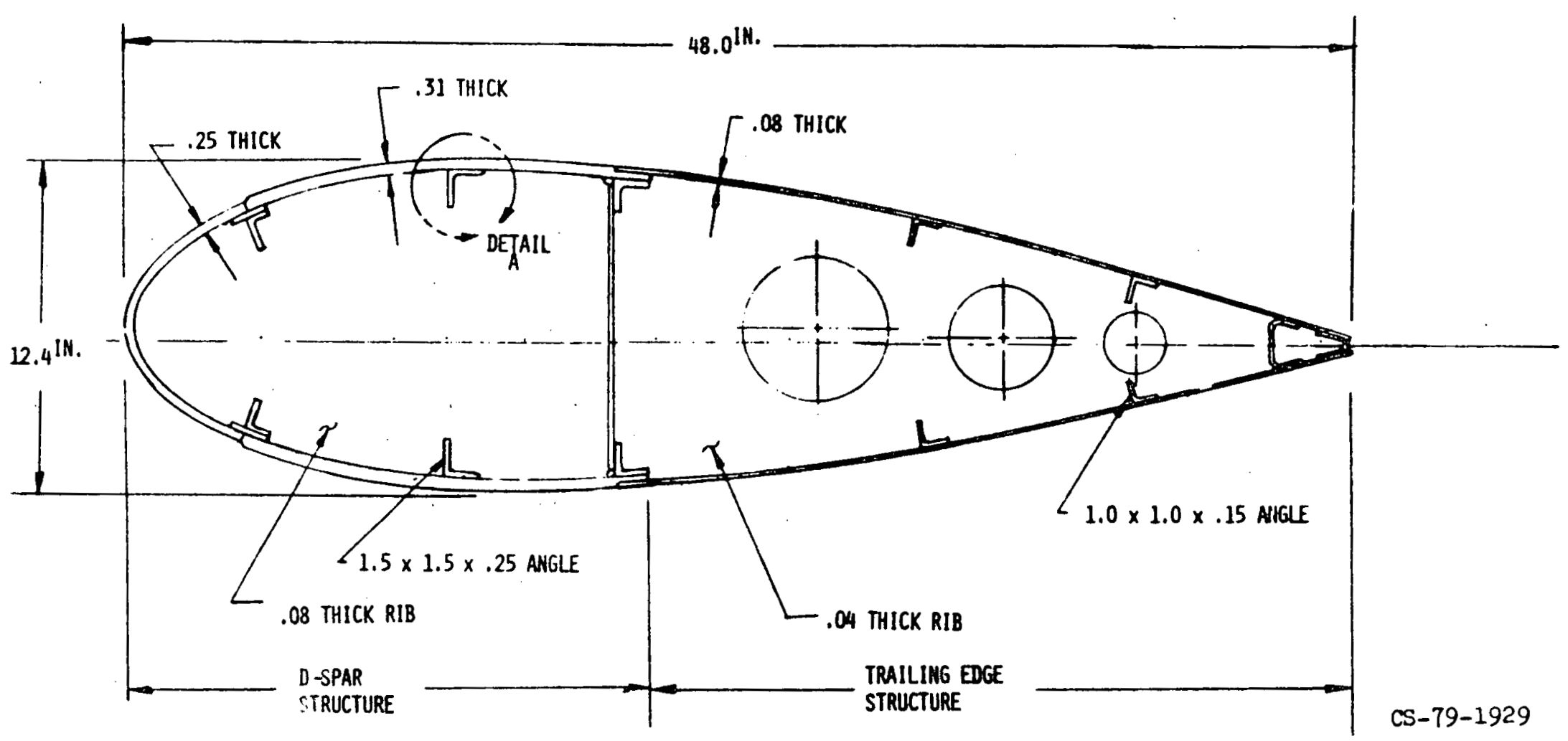

Figure 7. - Mod-OA blade typical cross section. 


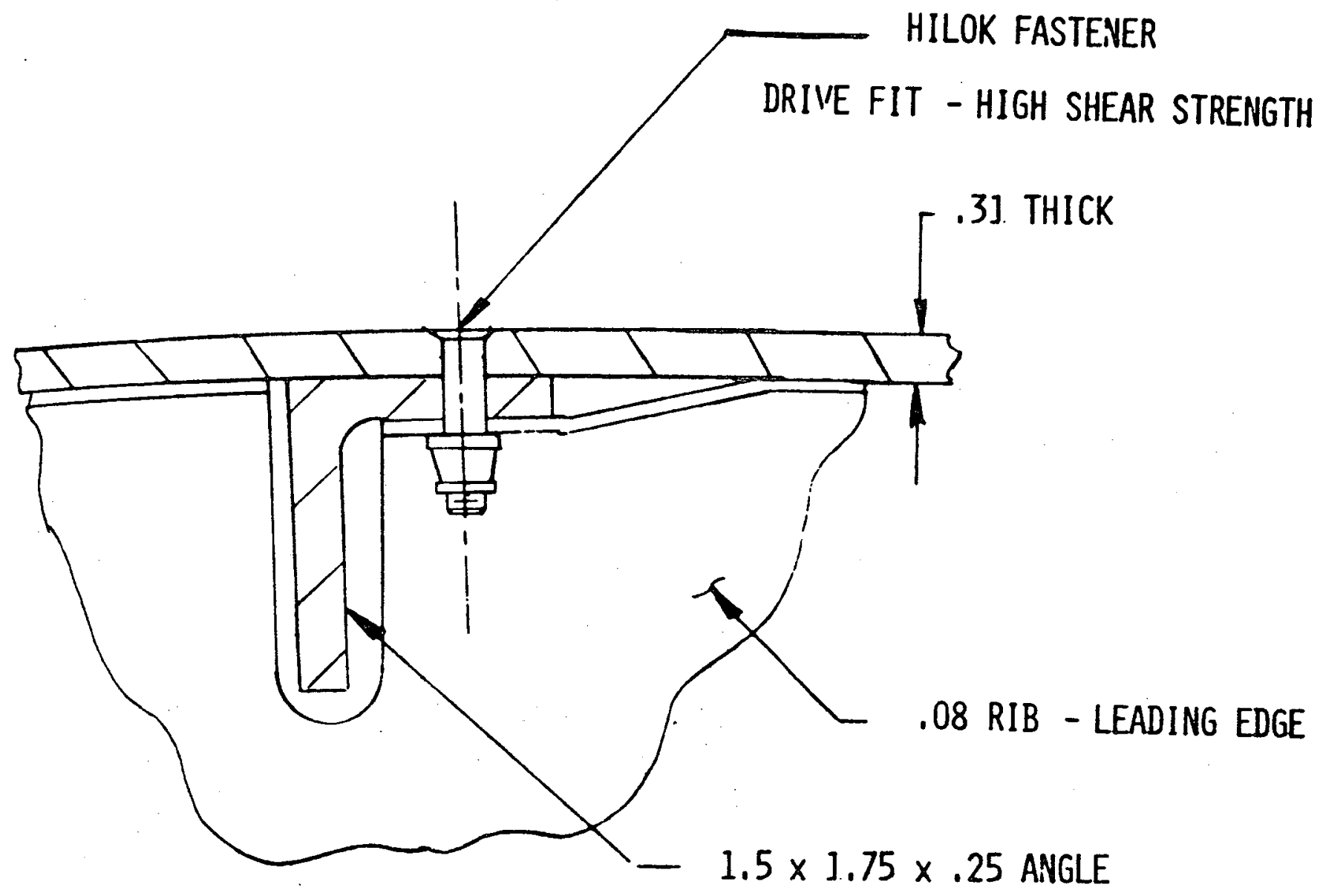

Figure 8. - Mod-OA blade fastener - detail A. 
MECHANICAL IIITERFACE
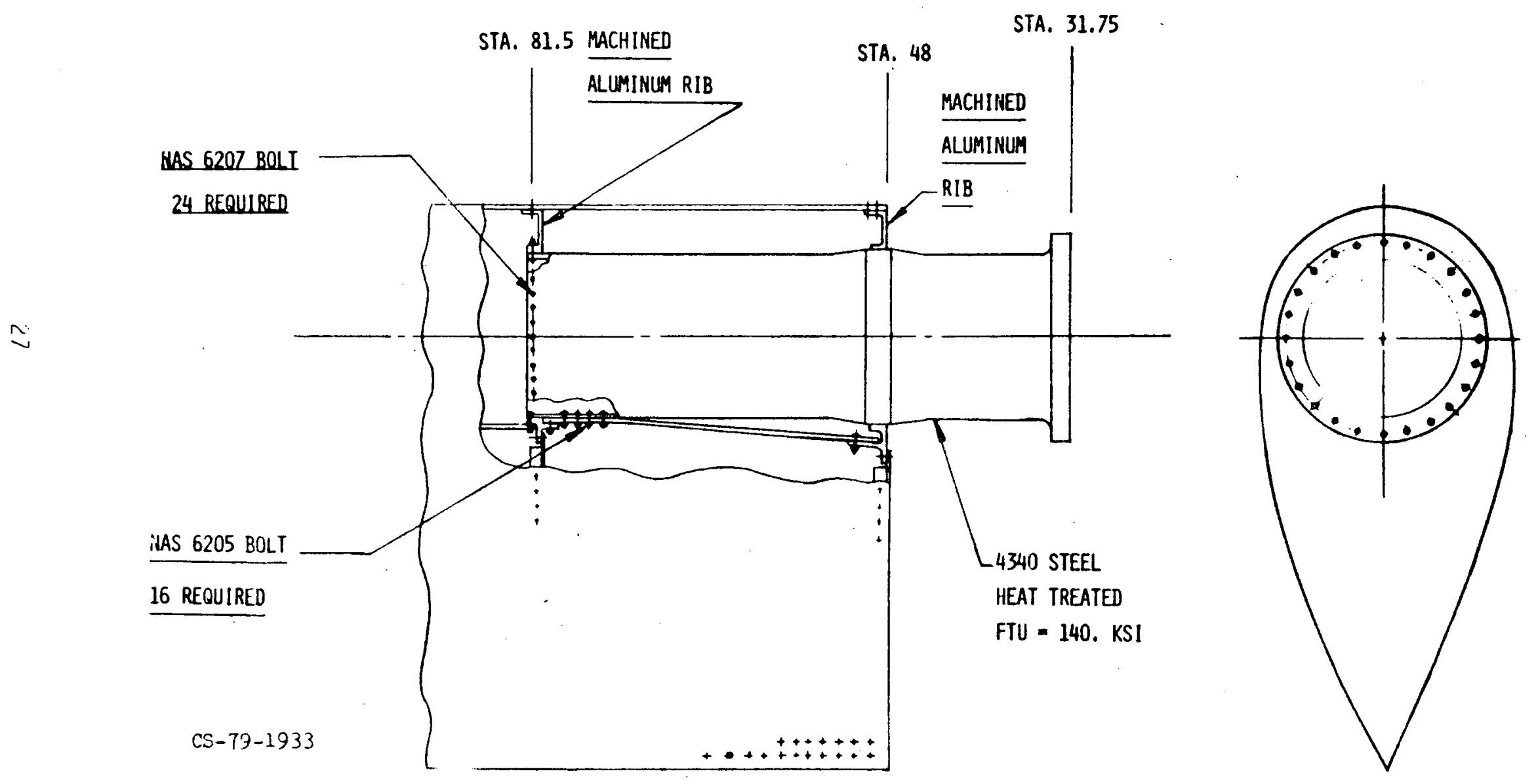

Figure 9. - Mod-OA blade root end details. 

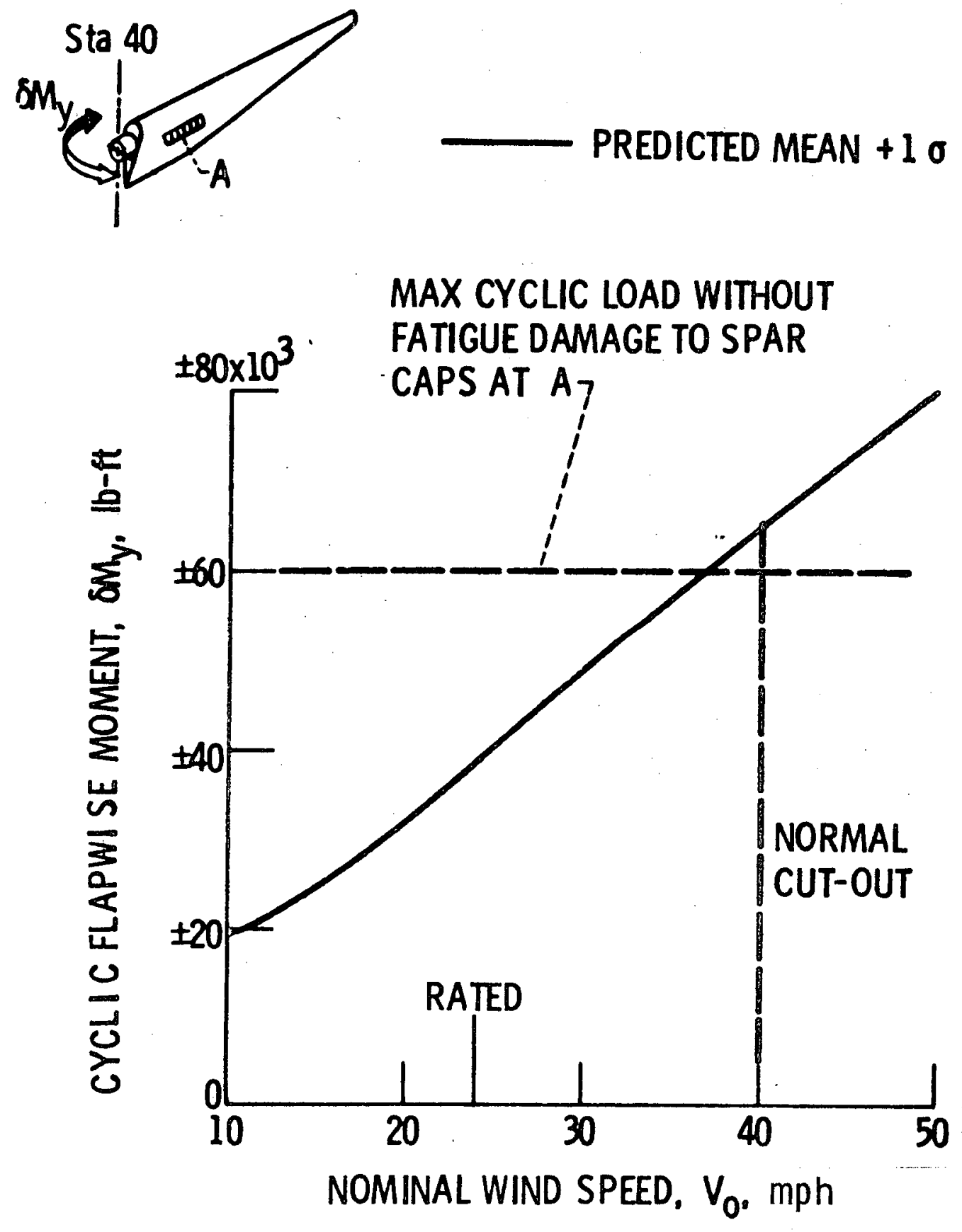

Figure 10. - Predicted cyclic flapwise bending loads for Mod-OA blades. 


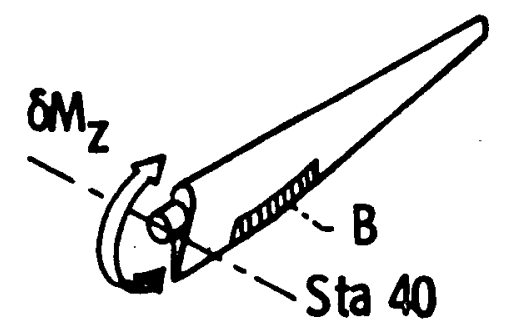

- PREDICTED MEAN $+1 \sigma$

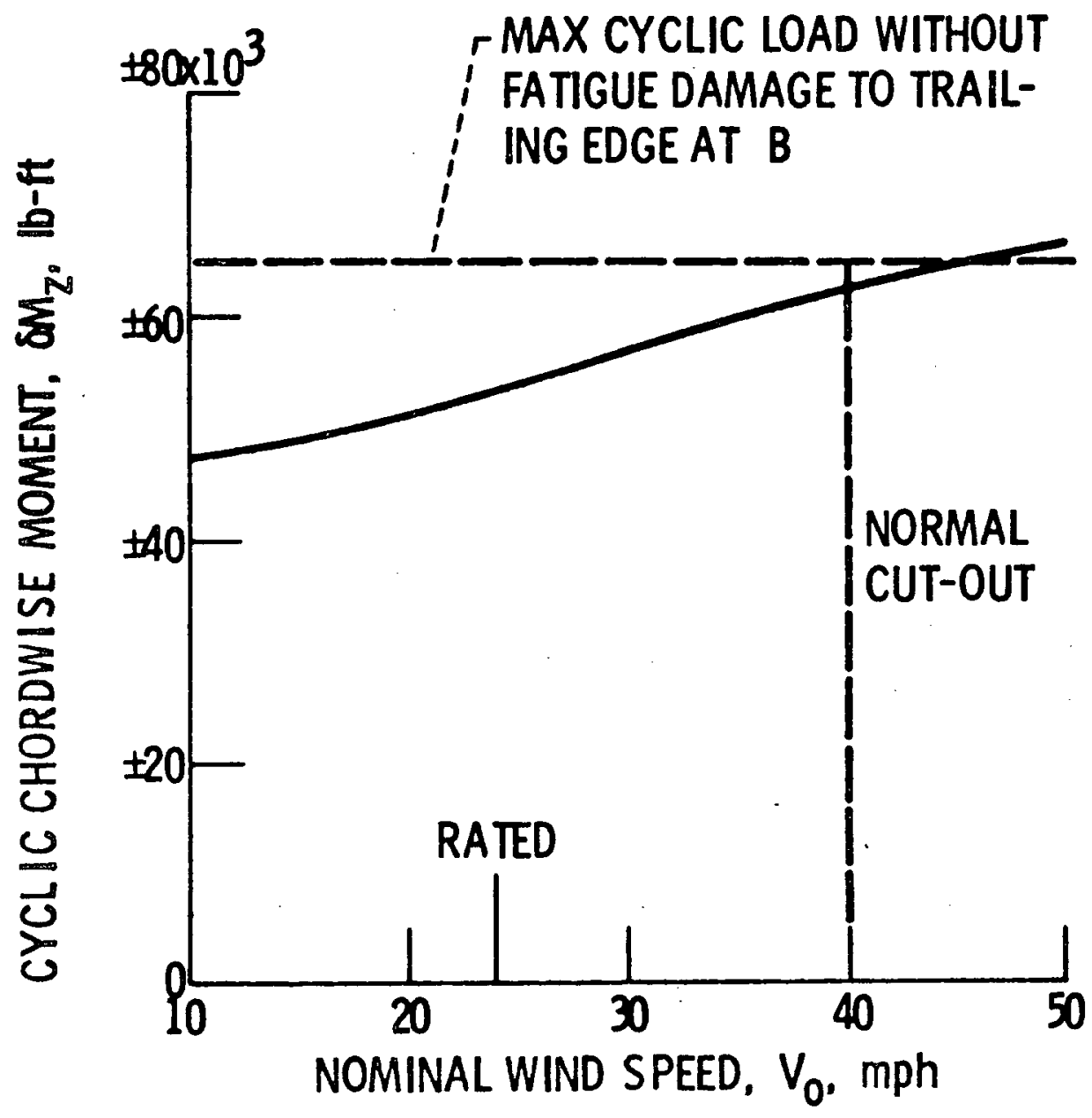

Figure 11. - Predicted cyclic chordwise bending loads for Mod-OA metal blades. 


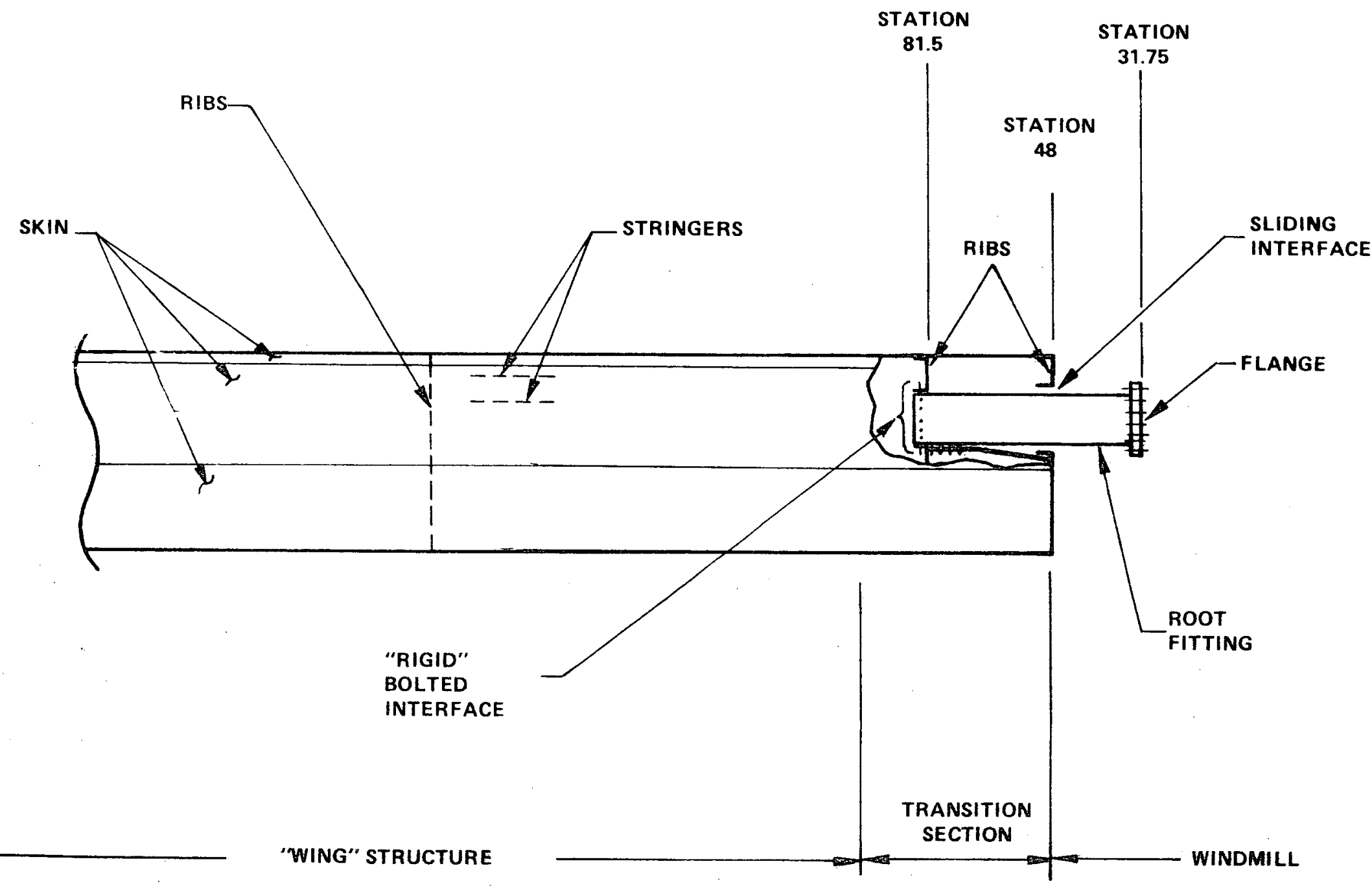

705322.1

Figure 12. - Mod-OA blade structural schematic. 


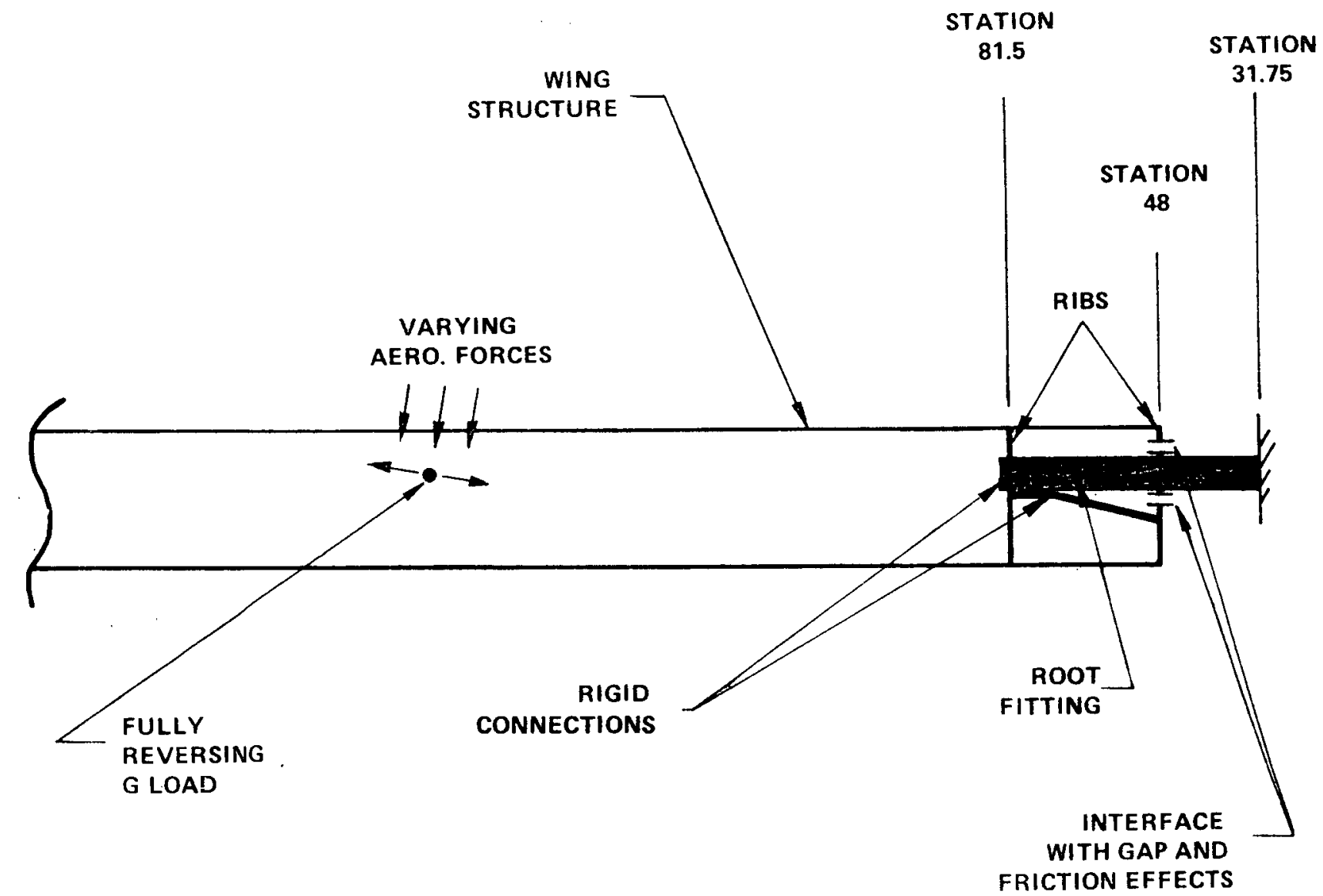

Figure 13. - Mod-OA transition section structural model. 


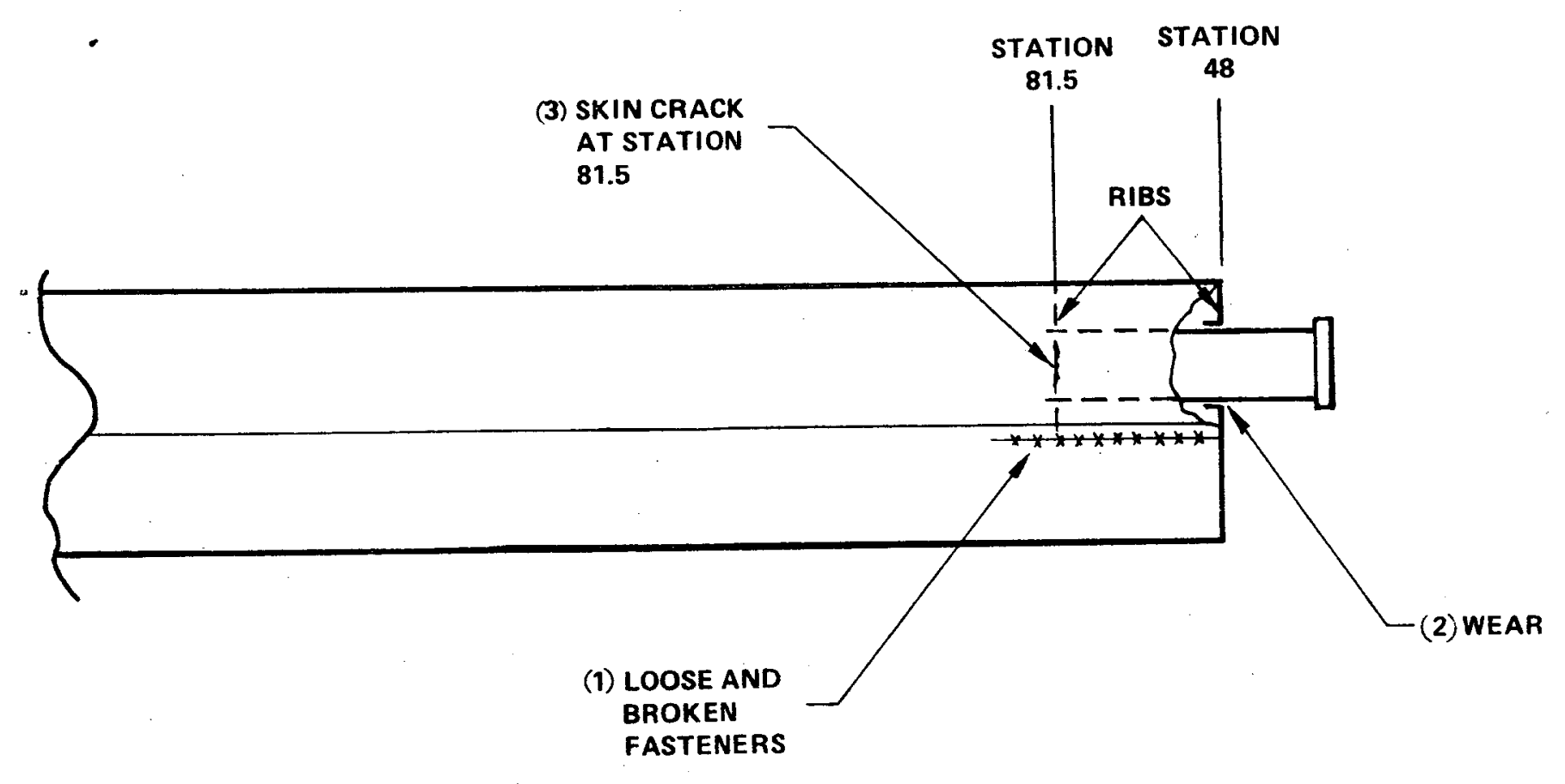

Figure 14. - Mod-OA blade damage. 


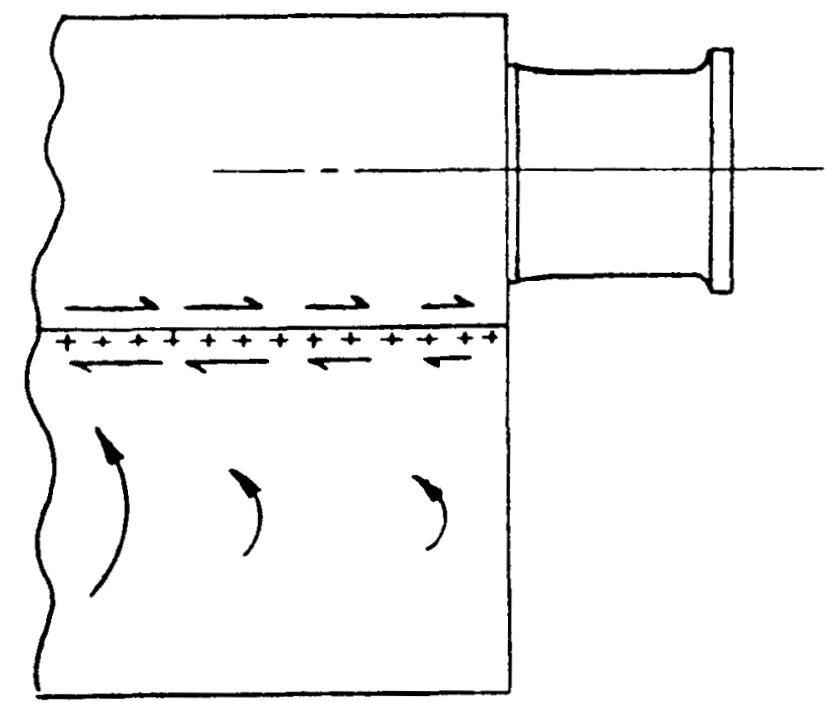

Figure 15. - Mod-OA blade trailing edge - U-spar fastener loads. 


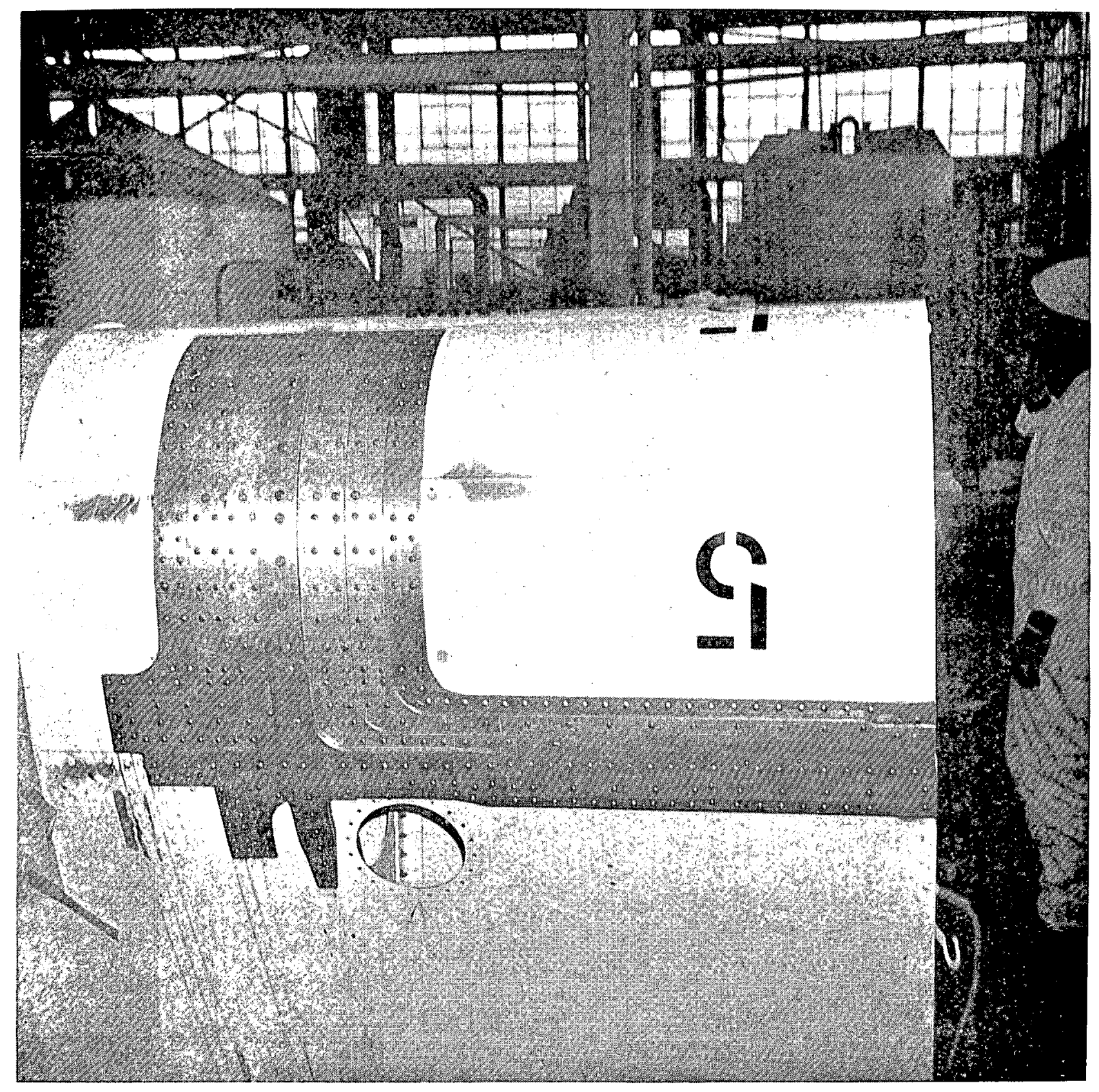

Figure 16. MOD-OA Blade SN 1005 Doublers 


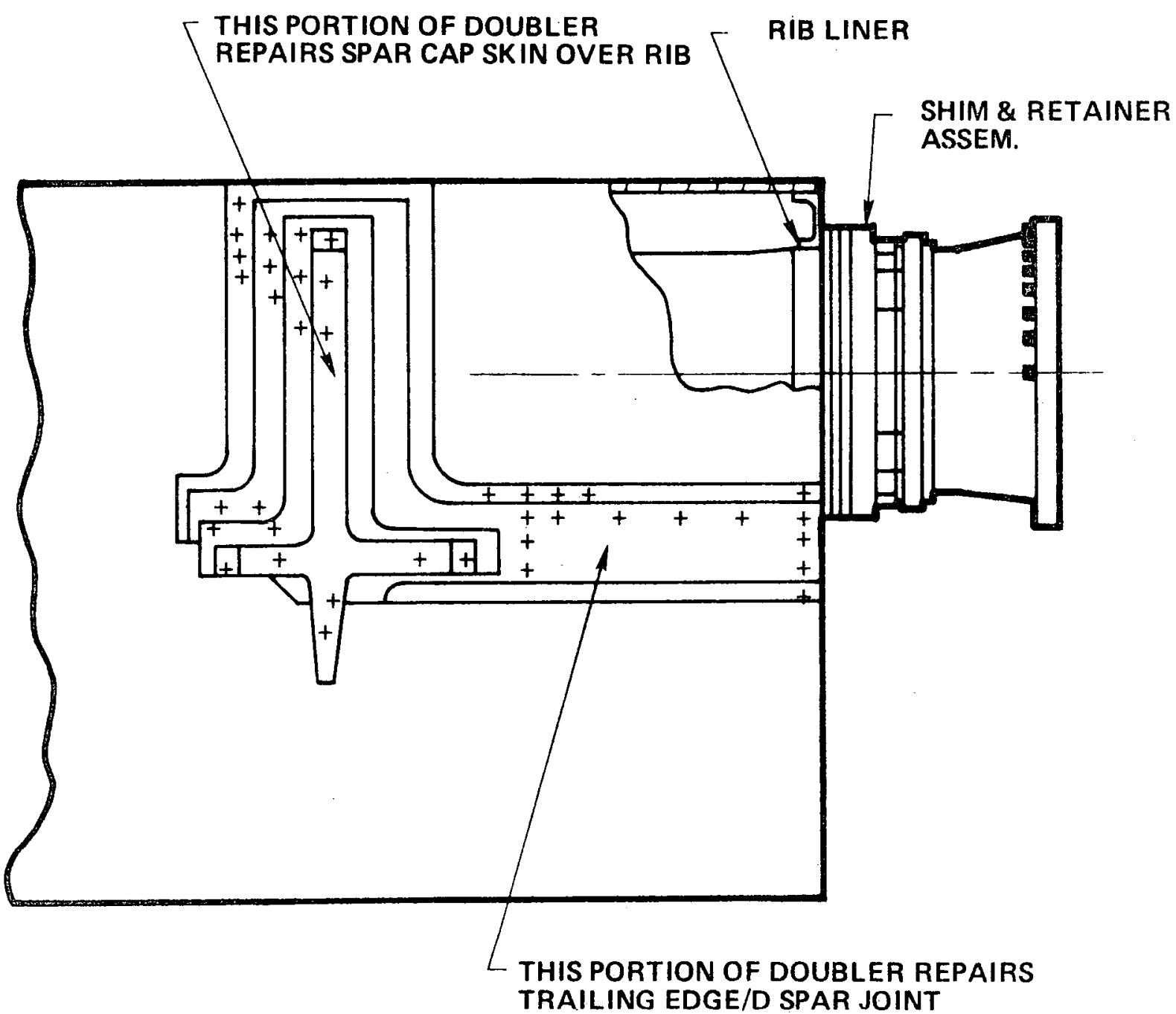

Figure 17. - Initial Mod-OA blade repairs and modifications. 


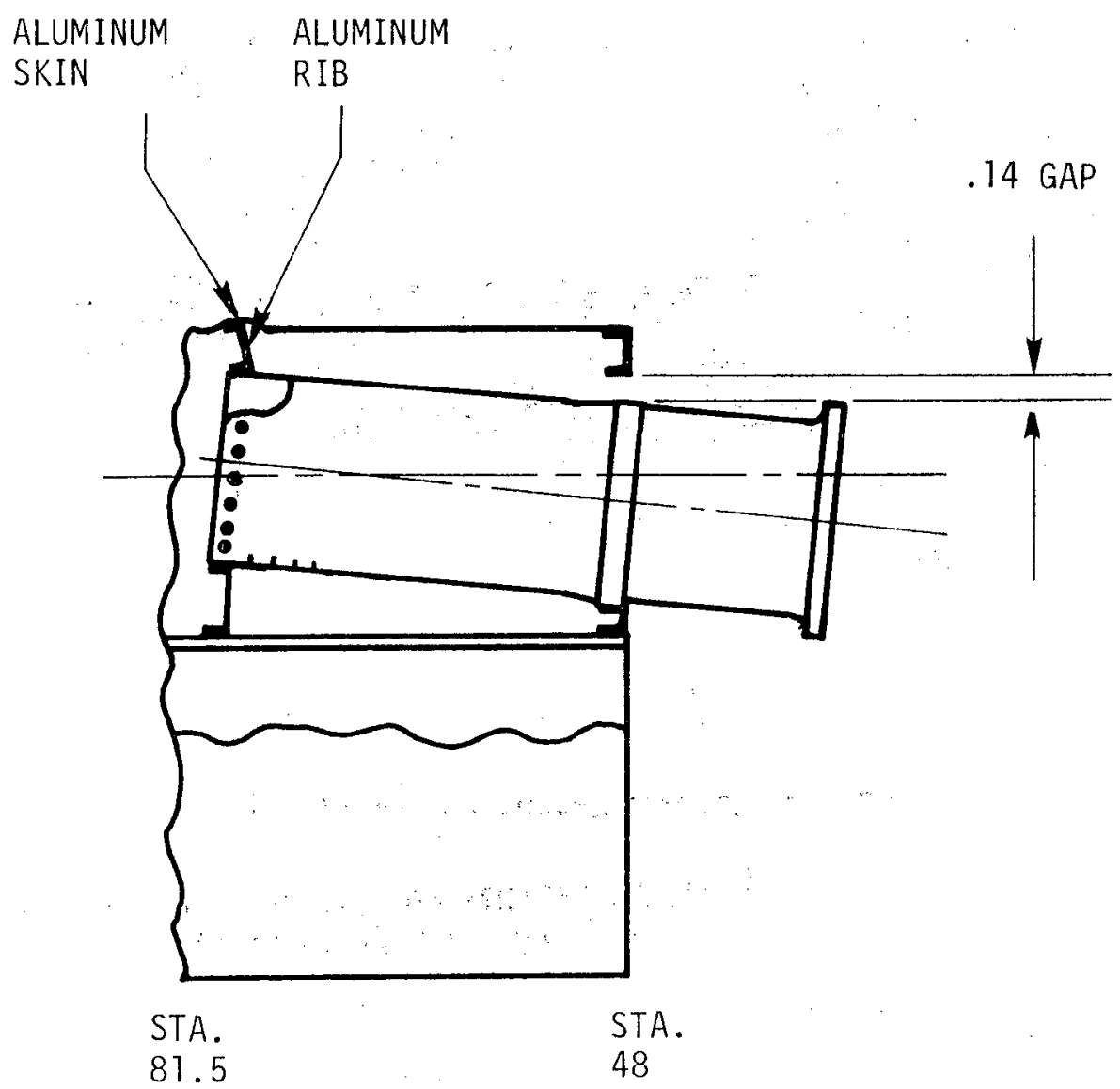

Figure 18. - Mod-0A blade station 48 interface wear problem. 


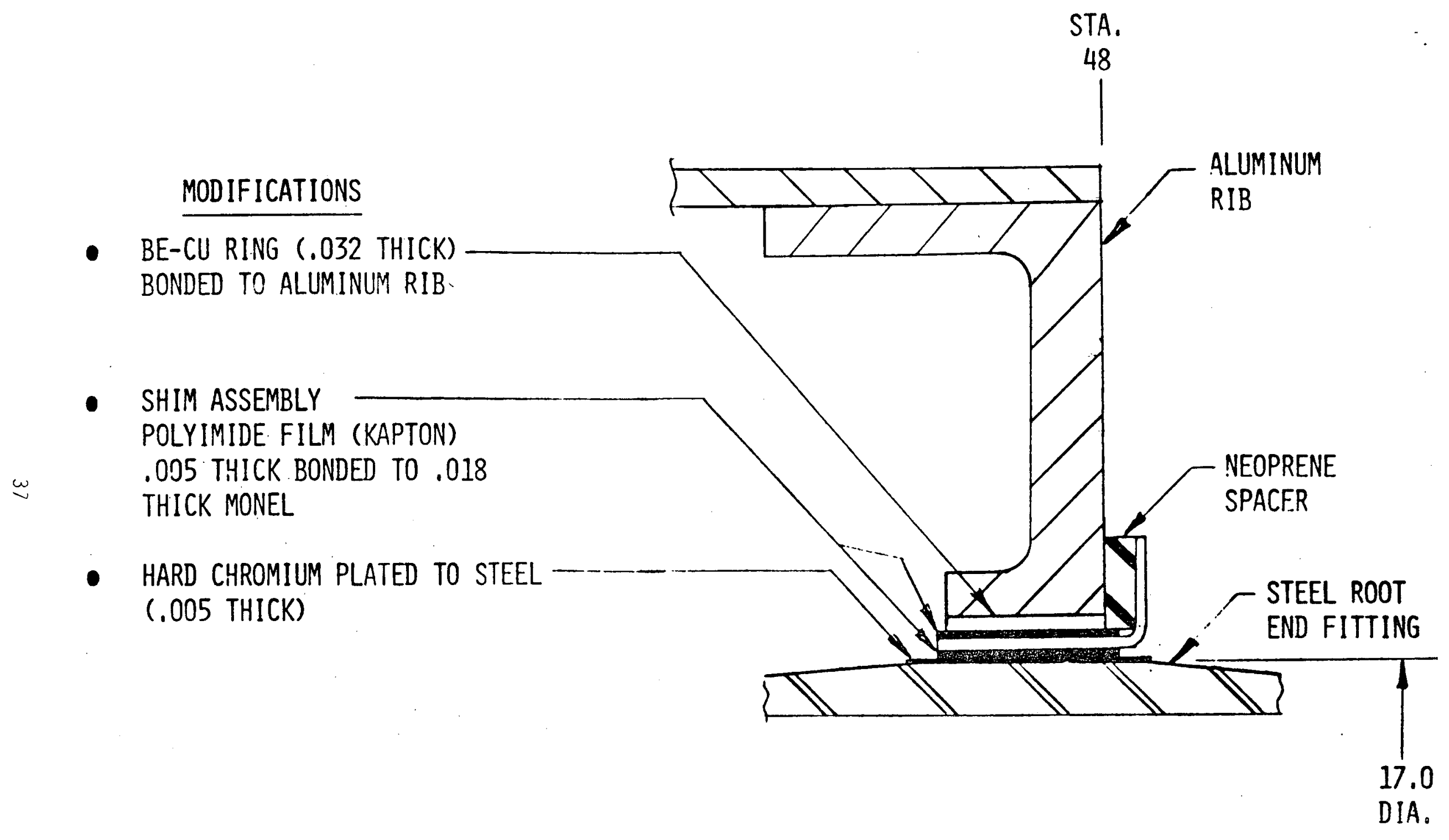

Figure 19. Jod-OA blade. Installation of beryllium copper liner and shims. 


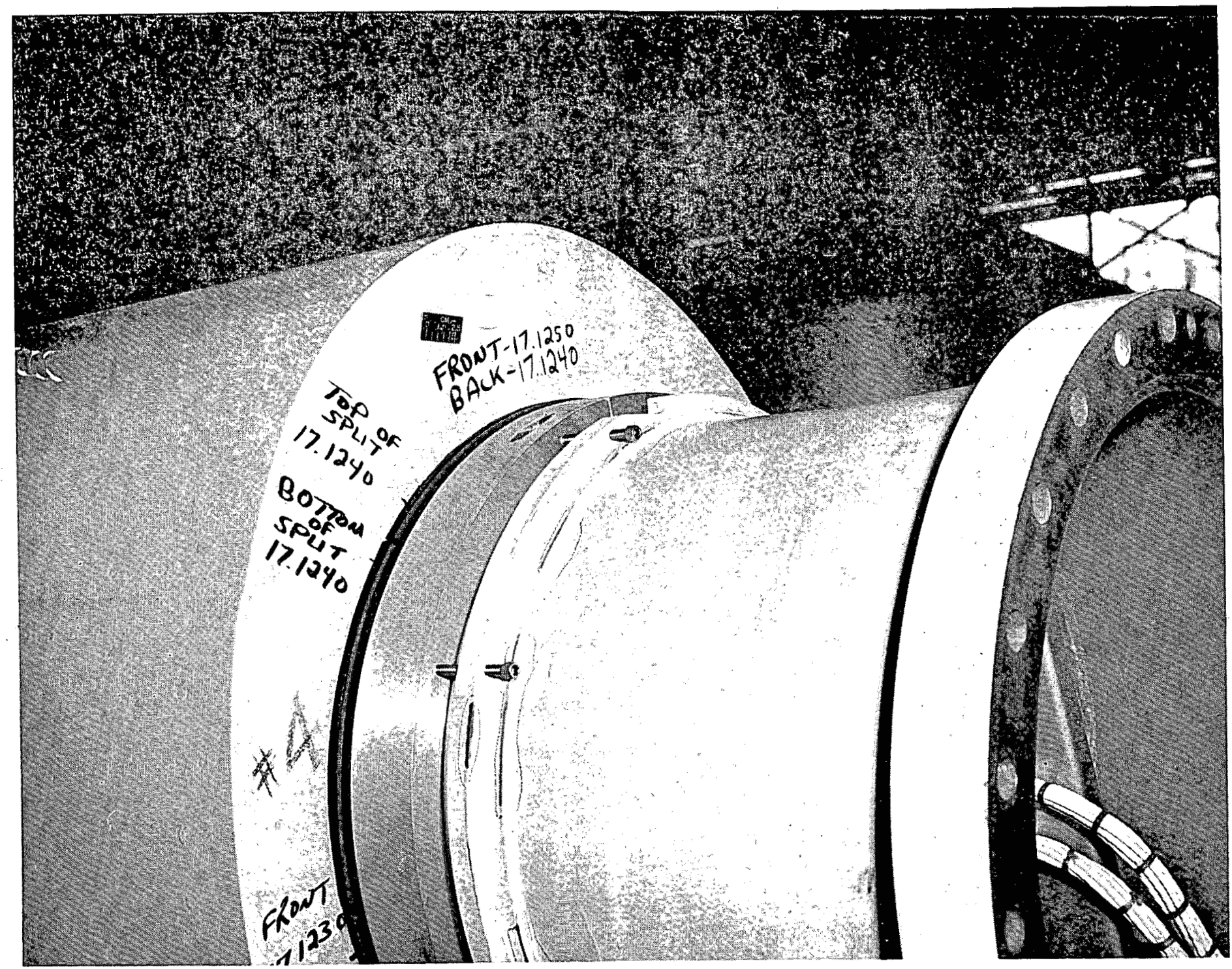

Figure 20. MOD-OA Blade SN 1004 with Station 48 Rib/Root Fitting Bearing Modifications 


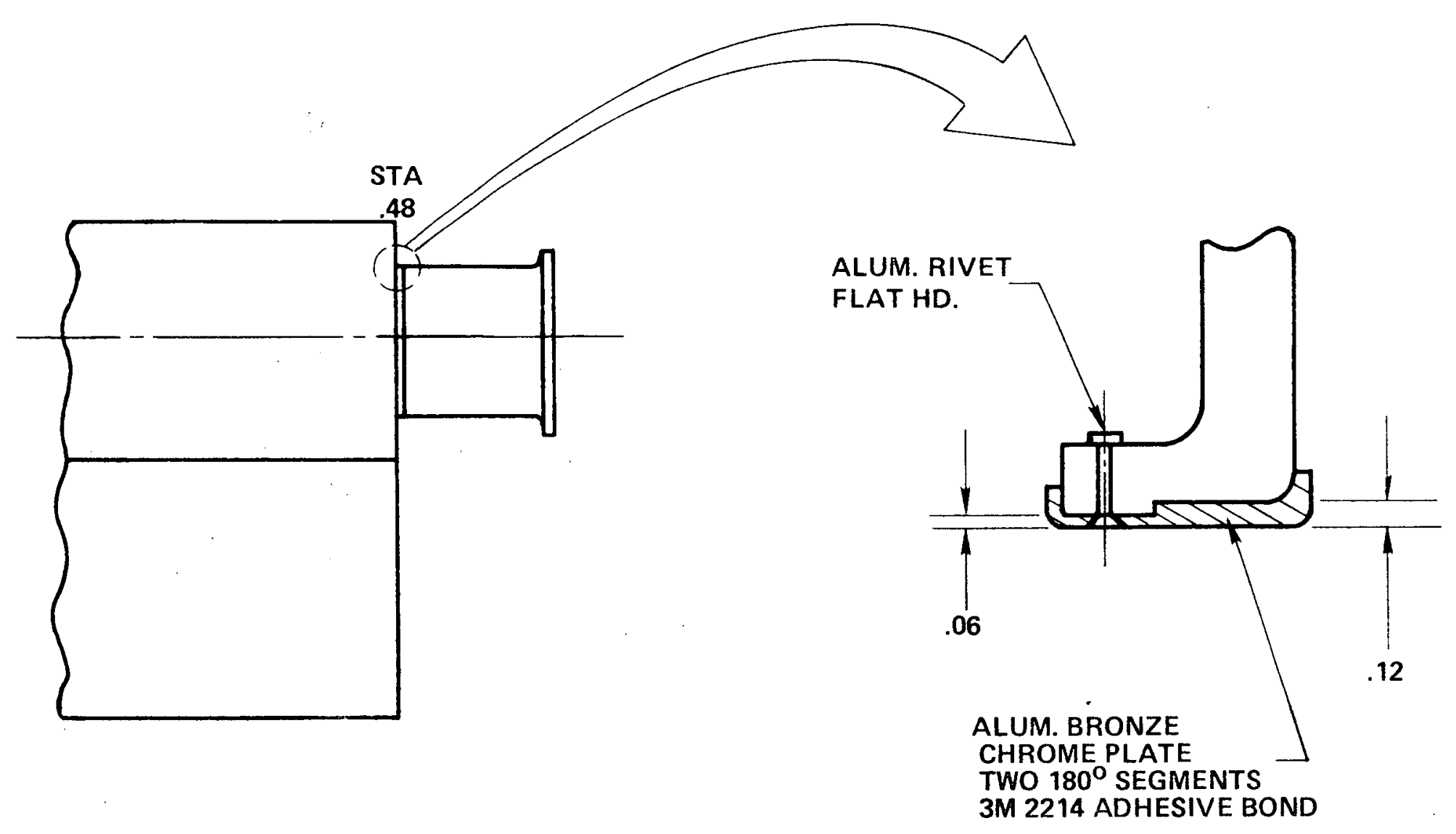

Figure 21. - Aluminum bronze liner for statinn 48 rib. 


\section{STA 48}

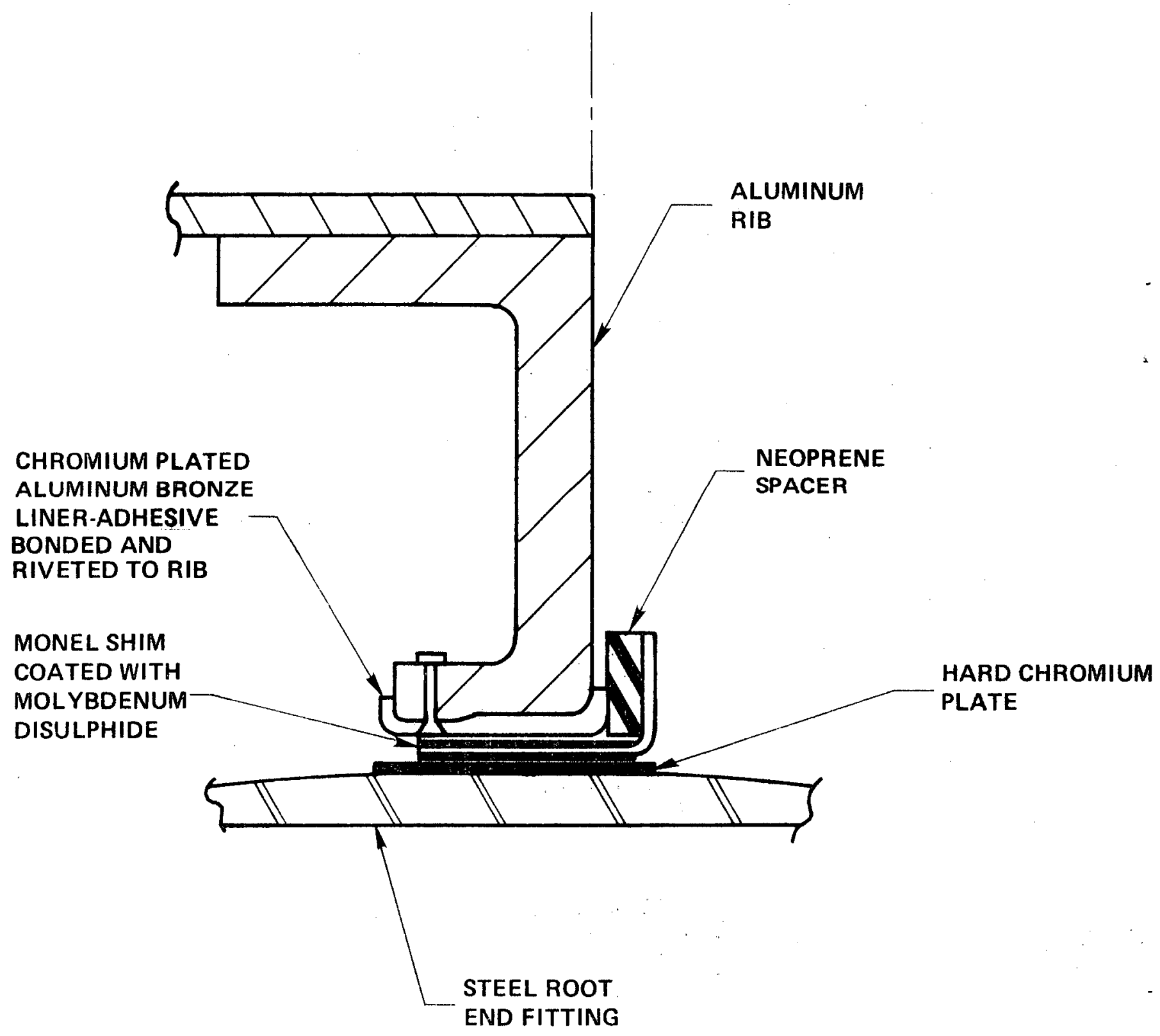

Figure 22. - Bearing assembly at station 48 with aluminum bronze liner. 